\title{
Neural correlates of written emotion word processing: A review of recent electrophysiological and hemodynamic neuroimaging studies
}

\author{
Francesca M.M. Citron \\ Cluster of Excellence "Languages of Emotion”, Freie Universität Berlin
}

Corresponding author:

Francesca Citron, PhD

Cluster "Languages of Emotion"

Freie Universität Berlin

Habelschwerdter Allee 45

14195 Berlin

Germany

Tel. +49 (0)30 83857869

Email address: fmm.citron@gmail.com

Running head: Neural correlates of emotion word processing

Key words: Emotion review, emotional valence, arousal, ERP, fMRI, written word processing, word recognition 


\begin{abstract}
A growing body of literature investigating the neural correlates of emotion word processing has emerged in recent years. Written words have been shown to represent a suitable means to study emotion processing and most importantly to address the distinct and interactive contributions of the two dimensions of emotion: valence and arousal. The aim of the present review is to integrate findings from electrophysiological (ERP) and hemodynamic neuroimaging (fMRI) studies in order to provide a better understanding of emotion word processing. It provides an up-to-date review of recent ERP studies since the review by Kissler et al. (2006) as well as the first review of hemodynamic brain imaging studies in the field. A discussion of theoretical and methodological issues is also presented, along with suggestions for future research.
\end{abstract}




\section{Introduction}

Research on emotion has reached a general consensus on the two-dimensional structure of affect. One dimension, emotional valence, describes the extent to which an affect is pleasant or unpleasant, and therefore elicits appetitive or defensive motivation (Lang, Bradley, \& Cuthbert, 1997). A second dimension, arousal, refers to the degree of activation associated with an affect, such as how intense/exciting or calming an emotion is (Lang et al., 1997; Reisenzein, 1994; Russell, 1980). This two-dimensional approach to the study of emotion has its origins in the study of the emotional space of single written words (e.g., Osgood, Suci, \& Tannenbaum, 1957), whereby many attributes of large word samples were rated using Likert scales and underlying common factors were extracted from the ratings. Based on this early work, three dimensions emerged: emotional evaluation, potency and activity, with the first two accounting for most of the variance in ratings. Theories of emotion mainly focused on evaluation (i.e., valence) and activity (i.e., arousal): some models consider them independent dimensions, as they explain unique residual variance and they have been shown to have very low reciprocal correlations (Feldman Barrett \& Russell, 1998), whereas other models do not view arousal as having a separate substrate, but rather, as representing activation of either the appetitive or defensive motivational system (Lang et al., 1997). In fact, some studies report significant correlations between valence and arousal to some extent, i.e., the more highly valenced (positive or negative) a stimulus, the higher its level of arousal (Bradley \& Lang, 1999). Ito, Cacioppo and Lang (1998) reported stronger correlations between negative stimulus valence and arousal and only weak correlations between positive valence and arousal. This again suggests that valence and arousal are not completely distinct and it also supports the idea that positive and negative valence are not simply the opposite ends of a continuum, but they differ with respect to other word properties (Cacioppo \& Berntson, 1994; Watson, Clark, \& Tellegen, 1988): besides arousal (Citron, Weekes, \& Ferstl, in press; Ito et al., 1998), familiarity (Citron et al., in press) and self-reference (Herbert, Herbert, Ethofer, \& Pauli, 2011; Herbert, Pauli, \& Herbert, 2010; Lewis, Critchley, Rotshtein, \& Dolan, 2007). 
Alternative models of emotion propose a set of basic, discrete emotions, such as joy, surprise, anger, fear, disgust and sadness, that are functional to the solution of basic adaptive problems and engage specific circuitries in the nervous system, common to different species and different cultures (see Levenson, 2011 for a review). Because the present review focuses on processing of a more general "emotional connotation" of written words, rather than specific emotions, dimensional models provide a better-suited framework.

It could be argued that a two-dimensional model of emotion might not describe emotional reactions, as it is based on linguistic categories. Nevertheless, evidence supporting such models comes from cross-cultural studies, showing for example that all known languages have words for the pleasant-unpleasant dimension (Wierzbicka, 1999) and that this dimension exists in all cultures (Russell, 1991), suggesting that humans' feelings are reflected in their spoken languages. Furthermore, both word and picture evaluations show an underlying bi-dimensional structure (Bradley \& Lang, 1999; Lang, Bradley, \& Cuthbert, 1999), thus arguing in favour of a common underlying neural mechanism driving emotion evaluation regardless of the stimulus modality.

Research on the neural correlates of emotion processing has also provided empirical evidence for the validity of a two-dimensional model. In particular, recent fMRI studies showed a dissociation in patterns of brain activation between emotional valence and arousal, whereby the orbitofrontal cortex and subgenual cingulate cortex reflect changes along the dimension of valence, while the amygdala responds more to arousal (Colibazzi et al., 2010; Lewis et al., 2007; Posner et al., 2009; Small et al., 2003; Winston, Gottfried, Kilner, \& Dolan, 2005) than to valence (Herbert et al., 2009; Kuchinke et al., 2005). However, the picture is more complicated when we look at the electrophysiological literature. Some studies using pictures or words as stimuli seem to provide support for the distinction between valence and arousal, whereby emotionally arousing stimuli 
differ from neutral stimuli at early, implicit and more automatic processing stages (between 200 and $300 \mathrm{~ms}$ after stimulus onset), whereas a distinction between positive and negative valence can be observed at later, explicit and more controlled processing stages, between 500 and 800 ms (e.g., Herbert, Junghofer, \& Kissler, 2008; Kissler, Herbert, Winkler, \& Junghofer, 2009; Schacht \& Sommer, 2009b; Scott, O'Donnell, Leuthold, \& Sereno, 2009). Other studies report only partially consistent results (e.g., Kanske \& Kotz, 2007; Schacht \& Sommer, 2009a; Schupp, Junghöfer, Weike, \& Hamm, 2004), whereby later processing stages discriminate only emotionally arousing stimuli from neutral stimuli, but do not distinguish between positive and negative valence. These differences might partly be due to higher sensitivity of the event-related potential (ERP) technique than functional magnetic resonance imaging (fMRI) to small differences in the materials tested, the task employed or the stimulus presentation duration, in particular with regards to the dynamic time course of emotion processing. On the other hand, this sensitivity seems to suggest that the overall picture of the distinction and relation between emotional valence and arousal is more complex than is assumed by the two-dimensional model.

\subsection{The present review}

Kissler, Assadollahi and Herbert (2006) presented a thorough review of electrophysiological (ERP) research on written emotion word processing. Since that review, the field has witnessed a flourishing of new studies and the emergence of new research questions. In addition, there has been rapid progress in understanding emotion word processing using functional imaging methods such as functional magnetic resonance imaging (fMRI). Therefore, the present paper presents an updated and integrative review of studies on the neural correlates of written emotion word processing employing both techniques. The use of the term "emotion word" in this paper refers to any word denoting a specific emotional reaction (e.g., sadness, happy) as well as to any other word characterised by a more general emotional connotation (e.g., flower, rain, prize, war). In the studies 
reviewed, these words may or may not induce an emotional reaction in the individuals processing them, depending on the type of task and the paradigm used.

The preferential or differential processing of emotional material compared to neutral material - often simply called the "emotion effect" in this review - might possibly be carried by a number of different stimulus properties other than its emotional content. For example, emotion words might be characterised by higher perceptual salience, a wider network of semantic connections, and stronger memory circuits. The last two properties are not usually considered affective (emotional) but rather "cognitive" properties. The emotion literature is rich with these and other examples, in which the boundary between emotion and cognition is not clearly determined at all and the reader must be aware of this still unresolved issue. If we consider as "cognitive" anything the brain does (e.g., perceptual processes), then emotions necessarily entail a cognitive component; whereas if we consider as "cognitive" higher-order appraisal processes, such as considering the social consequences of an event, emotions often occur in the absence of cognitive components (Levenson, 2011). A terminological distinction the reader will come across in the paper is the recurrent use of the word "cognitive" with regards to higher-order, explicit, demanding processes that require thinking or more elaborate stimulus encoding, as opposed to the term "physiological", with regards to primary, implicit, effortless processes associated with the visceral and somatosensory systems.

The focus of this review on studies employing presentation of written words, rather than spoken words, is motivated by the interest in the access to emotional verbal information, i.e., to lexico-semantic representations. Word presentation in the auditory modality entails additional nonverbal emotional information (e.g., prosody, intonation), that cannot easily be disentangled from the lexico-semantic information (e.g., Pell, Jaywant, Monetta, \& Kotz, 2011); it may also entail the implicit perception of a communicative intention by the speaker (e.g., Newman, 1978). For a recent 
review on emotional speech and language processing, that comprises clinical and neuroscientific studies employing words in both visual and auditory modalities, please refer to Kotz and Paulmann (2011).

\subsection{Words as a means to study emotion processing}

Studies of emotion processing have employed different types of emotionally valenced (positive or negative) material including odours, facial expressions, pictures and words. Emotion research seems to show that non-verbal stimuli elicit stronger emotion effects in the brain than words, apparently because of their biological preparedness to elicit emotional reactions (see Kissler et al., 2006). This claim is based on empirical evidence showing more consistent emotion effects on ERPs in response to pictures than words (Kissler et al., 2006). Nevertheless, only a few studies have directly compared words and pictorial material, providing interesting results. For example, Hinojosa, Carretié, Valcárcel, Méndez-Bértolo and Pozo (2009) reported a distinction between valenced and neutral words as well as pictures at relatively late processing stages, whereas early processing stages showed a similar effect only in response to pictures. In contrast, Schacht and Sommer (2009b) reported comparable ERP responses for facial expressions and words in early components, with later onset latency for words, suggesting a common system for emotion processing and a difference in the speed of meaning access.

Using fMRI, Kensinger and Schachter (2006) reported common patterns of activation for emotionally valenced words and pictures, with lower statistical power and therefore more circumscribed loci for words than pictures, i.e., the amygdala, dmPFC and vmPFC responded to emotional pictures, but only the left amygdala responded to words; in addition, only negative words elicited PFC activations. Kuchinke, Schlochtermeier and Jacobs (2011) suggest that the apparent advantage of pictures over words in eliciting brain activations can be accounted for by the greater visual complexity of pictures rather than their higher emotional significance. In fact, by 
manipulating emotional valence and stimulus complexity independently, they found a main effect of emotion, with enhanced amygdala activation for positive stimuli, independent of the material used or its complexity. In addition, main effects of stimulus complexity were found in extra-striate and prefrontal cortices, regions previously shown to more strongly respond to pictures than words.

In light of the current findings, we can conclude that words and other affective material show qualitatively similar emotional effects, but under most circumstances words are weaker in their effects. Nevertheless, emotional language is important enough to the understanding of human behaviour that it warrants investigation in its own right.

\subsection{Complementary techniques to study emotion word processing}

Kissler et al.'s (2006) thorough review of 40 years of ERP research revealed inconsistent results in the field due to the employment of obsolete measurement systems, little control of the experimental material, peculiar designs that are no longer used, and overly complex designs (which are still used). These issues have influenced recent electrophysiological as well as hemodynamic, functional neuroimaging studies, leading researchers to use carefully controlled material, simpler tasks, simpler designs and to consider the effects different tasks can have on word processing.

It is now widely recognised that ERP and fMRI techniques represent, at least in part, complementary methods to examine emotion processing in the brain. The ERP technique consists of the recording and subsequent processing of neuroelectrical activity by means of electrodes placed on the scalp. This technique is particularly suitable for examining the time-course of visual word processing because of its high temporal resolution, therefore allowing the observation of distinct stages of word processing that are influenced by emotional variables. The fMRI technique is instead an indirect measure of the hemodynamic activity associated with mental processes, which relies on changes in oxygen metabolism. This technique is characterised by high spatial (but low temporal) 
resolution and full-brain coverage, allowing observation of the brain structures activated during emotion processing. Full-brain coverage is particularly important for research on emotion because deep structures (basal ganglia, insula, cingulate cortex) are typically activated during emotion processing. Nevertheless, when electroencephalogram (EEG) is recorded from a high number of electrodes (at least 64), source estimation techniques that can compute estimates of the location of neural generators eliciting ERP components with reasonable spatial resolution and full-brain coverage.

The aims of the present review are: 1) to present an overview of the up-to-date literature in the field, comprising very recent studies; 2) to integrate results from electrophysiological and fMRI studies in order to gain a more complete picture of written emotion word processing; 3) to discuss current results with regards to the two-dimensional conceptualisation of emotion; 4) to consider theoretical and methodological issues; 5) to suggest directions for future research.

\section{Event related potential (ERP) studies of emotion word recognition}

Table 1 summarises all of the studies reviewed in this section, with details about the tasks and materials used, the behavioural results and the ERP components modulated by emotional variables. A key finding to emerge from this review is the time-course of the effects of valence and arousal on word processing, indexed by specific ERP components that have been consistently reported. Additionally, less consistently reported components, in particular very early ones, will also be reviewed and discussed in the sections below.

\subsection{Early posterior negativity (EPN) and late positive complex (LPC)}

Two ERP components have been repeatedly reported in response to the emotional content of verbal material. The early posterior negativity (EPN), shown in Figure 1, which peaks between 200 and $300 \mathrm{~ms}$ after stimulus onset, has an occipito-temporal scalp distribution and its amplitude is 
larger for emotionally valenced words (positive and negative) than neutral words during silent reading (Herbert et al., 2008; Kissler, Herbert, Peyk, \& Junghofer, 2007; Kissler et al., 2009), lexical decision (Citron, Weekes, \& Ferstl, 2011; Palazova, Mantwill, Sommer, \& Schacht, 2011; Schacht \& Sommer, 2009a; Scott et al., 2009) written word identification (Hinojosa, MéndezBértolo, \& Pozo, 2010) and emotional Stroop task (Franken, Gootjes, \& van Strien, 2009). This component has been associated with effortless initial stages of attention orientation during access to emotional information (Schupp et al., 2004). The EPN is task-independent, as its effect is not modulated by depth of processing (Schacht \& Sommer, 2009a), the emotional nature of the task (Kissler et al., 2006), or the self-referentiality of the emotional stimulus (Herbert et al., 2010); Nevertheless, a minimal post-perceptual elaboration is needed for the emotion effect to appear (Hinojosa et al., 2010). This suggests that EPN indexes automatic, implicit processing of emotion.

INSERT FIGURE 1 HERE

This early stage of processing (200-300 ms) is generally associated with lexical access, i.e., mapping of the visual stimulus with its corresponding lexical representation (e.g., Abdullaev \& Posner, 1998). By using rapid serial visual presentation (RSVP) designs, a similar occipitotemporal negativity has been observed, and is called the recognition potential (RP). This component is sensitive to the meaningfulness and task-relevance of visually presented words. The RP has mostly been studied with verbal material, but it also appears in response to picture and face stimuli (Martin-Loeches, 2007). It appears to originate in the fusiform gyrus, or visual word-form area (Hinojosa, Martin-Loeches, \& Rubia, 2001) and this suggests that a word's emotional connotation can be accessed in parallel with the retrieval of its visual form (Kissler et al., 2006). A source analysis using the minimum-norm least square solution (MNLS, Hamalainen \& Ilmoniemi, 1994) on the EPN component revealed its origin from the left extra-striate cortex (Kissler et al., 2007) and a source analysis using the software BESA (Scherg \& Berg, 2000) located its dipole pair in the 
fusiform gyrus (Schacht \& Sommer, 2009a). These apparently differing findings can be reconciled: in fact, both extra-striate cortex and fusiform gyrus are part of the inferotemporal brain regions and more generally of the ventral visual processing stream (Mishkin, Ungerleider, \& Macko, 1983).

There exists mixed evidence regarding a lateralisation of the EPN: a few studies using emotional pictures reported emotional effects to be more pronounced over the right electrodes (Junghöfer, Sabatinelli, et al., 2001; Schupp et al., 2006), in line with a preferential processing of emotion in the right hemisphere, whereas only a couple of studies using single words reported more pronounced effects over the left electrodes (Herbert et al., 2008; Kissler et al., 2007), possibly due to the recruitment of language-related regions.

The late positive complex (LPC), also called late posterior positivity (LPP; see Figure 2), peaks between 500 and $800 \mathrm{~ms}$ and has a centro-parietal scalp distribution. This component has been shown to respond to the emotional content of verbal stimuli and, more specifically, to the valence dimension. In fact, its amplitude is usually larger for emotionally valenced stimuli than neutral stimuli (Carretié et al., 2008; Hinojosa et al., 2010; Kanske \& Kotz, 2007; Schacht \& Sommer, 2009a), indexing sustained processing. However, amplitude differences between positive and negative stimuli (Kissler et al., 2009), a general advantage of positive words over neutral and negative words (Herbert et al., 2008; Herbert, Kissler, Junghöfer, Peyk, \& Rockstroh, 2006; Kissler et al., 2009), or an advantage of negative words over neutral (and positive) words (Gootjes, Coppens, Zwaan, Franken, \& van Strien, 2011; Hofmann, Kuchinke, Tamm, Võ, \& Jacobs, 2009; Kanske \& Kotz, 2007; Schacht \& Sommer, 2009b) have also been reported for this component. Furthermore, larger amplitudes of this component for neutral words than valenced words has also been reported in word identification (Hinojosa et al., 2009) and lexical decision tasks (Citron, Weekes, et al., 2011), possibly indexing higher processing demand for less salient, neutral stimuli. In fact, because emotional stimuli are more salient, more easily and quickly processed, they require 
less sustained attention and evaluation to be responded to; neutral stimuli, instead, are less motivationally relevant and might require more evaluative effort to be distinguished from the nonword distractors. These contrasting results might be due to differences in materials (e.g., nouns vs. adjectives, high-frequency vs. low-frequency words, different word length ranges) and tasks, but the important point here is that the LPC seems to more subtly discriminate the emotional valence of written words than the EPN.

INSERT FIGURE 2 HERE

The LPC belongs to a bigger family of positive components, such as the P300, which are more generally associated with attention orientation toward and evaluation of a stimulus in order to respond according to task requirements. These components also index recollection of a mental representation or memory and their amplitude or latency differences are correlated with behavioural performance (Polich, 2007). The LPC is modulated by the type of task and also by the emotional self-relevance of its content: in particular, Fischler and Bradley (2006) reviewed studies in which discrimination of emotional material from neutral material was found only when the emotional content of the stimuli was task-relevant or when semantic processing was required, but not during lexical decision or orthographic judgement. Another study found emotion effects on the LPC with lexical and semantic tasks, but not with a more shallow structural task (Schacht \& Sommer, 2009a). In addition, Hinojosa et al. (2010) reported emotion effects during word identification with nonwords as background stimuli, but not with non-recognisable stimuli. LPC amplitude has also been shown to vary with the self-referentiality of the emotional stimulus, being larger for words describing self-referential emotional experiences (positive emotions in particular, e.g., my happiness) than either words describing the same experiences but in reference to other people (e.g., his/her success) or words with no specific reference (Herbert et al., 2011; Herbert et al., 2010). 
Together, these results suggest that the LPC indexes more controlled, explicit processing of emotion, as opposed to the EPN component.

\subsection{Other ERP components}

Herbert et al. (2006) reported larger amplitude for emotionally valenced words than neutral words on the P2 component (180-250 ms) over centro-parietal sites. Larger P2 amplitude for positive words than neutral words was also reported by Kanske and Kotz (2007), between 210 and $300 \mathrm{~ms}$; this was followed by the N400 component (390-590 ms), showing larger amplitude for neutral words than valenced ones, particularly pronounced in the left anterior region (see also Gootjes et al., 2011; Sass et al., 2010). The P2 effects resemble the EPN response to the general emotional content of the stimuli; their time-windows overlap, though the scalp distribution is slightly different. The N400 indexes lexical access (Lau, Phillips, \& Poeppel, 2008) and lexicosemantic integration processes (Kutas \& Federmeier, 2000); thus, the effect found might reflect facilitated lexical or semantic processing for emotional stimuli, in line with the reaction time results (Kanske \& Kotz, 2007).

Very early components have also been reported. Scott et al. (2009) found larger amplitude for valenced words than neutral words on the P1 (80-120 ms). This effect was found only for highfrequency words. A similar interaction between emotion and word frequency occurred on the subsequent N1 (135-180 ms). These results suggest that emotional content of a word affects very early visual (P1) and attentional (N1) components. According to Sereno and Rayner (2003; Sereno, Rayner, \& Posner, 1998), word frequency effects index a very early onset of lexical access, although models of word recognition propose a later onset, around 200 ms (e.g., Marslen-Wilson \& Tyler, 1980) or on the N400 component (Lau et al., 2008). Therefore, the interaction of word frequency and emotion on the N1 suggests that emotion affects very early lexical access. A very early negativity (80-120 ms) with larger amplitude for words with higher arousal level was reported 
by Hofmann et al. (2009), supporting the N1 findings mentioned above. Finally, larger P1 amplitude for threatening words than pleasant ones was reported by Sass et al. (2010) only in male participants. This study is the first one to investigate individual differences in the time-course of emotion word recognition. In addition to a preferential processing for threat-related words on the P1, they also reported larger amplitude of the N2 component for pleasant words than threat-related words in males. Female participants showed a different effect: later P3 latency in response to threat-related words than to pleasant ones.

\subsection{What have ERPs told us about emotion word processing?}

The general emotional content of verbal material affects word processing at early stages (e.g., EPN), when automatic, implicit processes are at play and when no discrimination between positive and negative valence is yet apparent. Furthermore, this effect has also been found using the RSVP paradigm, i.e., a sustained high-speed input stream, with enhanced effects for faster rates: 3 words vs. 1 word per second (Herbert et al., 2008; Kissler et al., 2007). These results replicate previous work with picture stimuli by Junghöfer, Bradley, Elbert \& Lang (2001), who first employed this paradigm in emotion research; their study showed rapid, selective attention capture by complex emotional pictures ( 3 or 5 per second), independent of formal properties such as colour, brightness, spatial frequency, and complexity. These findings are in line with the proposal of a very short-term conceptual memory store (Potter, 1975) and extend it to emotional verbal material.

The EPN effect has often been interpreted as an arousal effect, which is plausible according to Russell’s $(1980,2003)$ proposal of independence between these dimensions. Nevertheless, within the framework of Lang et al. (1997), that considers valence and arousal intrinsically associated, emotionally valenced and neutral stimuli do not only differ along the arousal dimension, but also along valence. Therefore, the EPN effect can more precisely be attributed to a general 
"emotionality" effect, in which valence and arousal dimensions are intrinsically associated and not discernible.

At later stages (e.g., LPC), when more controlled, explicit cognitive processes take place, subtler discriminations along the valence dimension are observed. Results are mixed with regards to the direction of the effects: in some cases positive words show a processing advantage over neutral or neutral and negative words, in others, negative words show an advantage over positive ones, and yet other times a general distinction between valenced and neutral words is observed. For these effects to show up, a minimum degree of cognitive involvement must be required by the task.

It is here suggested that emotional valence affects higher-order cognitive processes and can be conceptualised as a more "cognitive" dimension, in the sense that it involves more elaborative and evaluative processes, as opposed to more stimulus-driven perceptual processes. No conclusions can be drawn yet on the role of arousal in emotion word processing, but the fMRI literature reviewed below, as well as some very recent ERP studies, will help to clarify this issue. Another open question regards the nature of the processes involved in emotion word processing: Which processes are involved: visual/perceptual processes, selective attention, lexical activation, retrieval of emotional experiences? Does emotion word processing automatically involve emotion-based processes? Or are emotion words just cognitively salient and/or relevant stimuli? Again, the fMRI literature review and the subsequent comparison of the findings using that technique with the ERP results will in part answer these questions.

INSERT TABLE 1 HERE OR AT THE END OF THE MANUSCRIPT

\section{Functional magnetic resonance imaging (fMRI) studies of emotion word recognition}


Hamann and Mao (2002) were the first to show amygdala activation in response to positive written word stimuli as well as negative ones, when asking participants to covertly experience the feelings elicited by positive, negative and neutral words. In particular, highly arousing positive and negative words activated the left amygdala when compared to neutral words. This result was replicated by Kensinger and Schacter (2006) using non-emotional semantic tasks. Bilateral amygdala activation for emotionally valenced words has also been reported by Straube, Sauer and Miltner (2011) during both valence and grammatical class categorisation. These results add to findings of bilateral amygdala activation in response to negatively valenced, threat-related words (Isenberg et al., 1999; Kanske \& Kotz, 2011; Nakic, Smith, Busis, Vythilingam, \& Blair, 2006) and suggest a functional role of the amygdala in response to intense emotional stimuli in general, that is not restricted to the dimension of negative valence only.

An interesting study from Sabatinelli, Bradley, Fitzsimmons and Lang (2005) showed amygdala activation in response to increasingly arousing pictorial stimuli to covary with activation of the inferotemporal visual cortex. Even though this result was obtained during picture viewing and not word processing, it relates back to the ERP findings previously reviewed and in particular to the localisation of the EPN source within the inferotemporal cortex. This region is implicated in directing attention toward and processing motivationally relevant stimuli (Lang et al., 1998). Amygdala and inferotemporal cortex activations are functionally integrated through dense reciprocal connections during emotional stimulus processing (Sabatinelli et al., 2005).

Some fMRI studies have investigated the two-dimensional model of emotion by manipulating emotional valence and arousal independently. Using a parametric design, Lewis et al. (2007) presented participants with positive and negative words that varied systematically along the dimension of arousal, during a self-referential task. They showed activation of the orbitofrontal cortex and the ventral anterior cingulate cortex (vACC) in response to emotional valence, whereas 
the amygdala, anterior insula and pallidum responded to arousal, thus supporting a distinction between the two putative dimensions of emotion at the neural level. Orbitofrontal cortex activation has been associated with decision making (Bechara, Damasio, \& Damasio, 2000), but also with processing of emotion and reward (Kringelbach, 2005). Ventral ACC activation is associated with error detection (Botvinick, Nystrom, Fissell, Cater, \& Cohen, 1999), as well as emotional conflict (Kanske \& Kotz, 2011); dorsal ACC, instead, is involved in error and feedback processing (Polli et al., 2005) - thus having a more evaluative function - as well as conflict processing irrespective of emotional content (Kanske \& Kotz, 2011), and reward-based decision making (Bush, Luu, \& Posner, 2000). These functions suggest that emotional valence involves higher-order, cognitivelybased and evaluative processes. On the other hand, amygdala activation has been shown in response to highly arousing emotional stimuli (Garavan, Pendergrass, Ross, Stein, \& Risinger, 2001; Sabatinelli et al., 2005; Winston, O'Doherty, \& Dolan, 2003); it also codes more perceptual stimulus aspects, such as salience (Wager, Phan, Liberzon, \& Taylor, 2003) and relevance to current mood (Herbert et al., 2009), as opposed to ACC, which is activated during more cognitively-driven tasks such as emotional recall, semantic processing and episodic memory (Cabeza \& Nyberg, 2000). Anterior insula is associated with integration of autonomic and visceral information with emotional and motivational functions, whereas posterior insula codes somatosensory, vestibular and motor integration (Jones, Ward, \& Critchley, 2010). Overall, the functions associated with the specific activations identified with fMRI support the idea that the arousal dimension involves more automatic, perceptual and physiological reactions.

Posner et al. (2009) asked participants to evaluate the valence and arousal dimensions of words that denote specific emotions by encouraging participants to think of situations or memories associated with each emotion. They observed activation of bilateral dorsal anterior and posterior CC, left dorsolateral and bilateral medial PFC and left caudate in response to emotional valence, confirming a cognitive and evaluative component of this dimension, but also suggesting the 
involvement of explicit, top-down and memory-related processes elicited by the specific task used. In fact, even though the medial PFC is activated in response to emotional stimuli independently of the material, induction method or task used (Phan, Wager, Taylor, \& Liberzon, 2002), the dorsolateral PFC is activated during integration of sensory and mnemonic information, implementation of cognitive control (MacDonald, 2000) and working memory processes (Levy \& Goldman-Rakic, 2000). Arousal also activated brain regions associated with more cognitively and memory-based processes, i.e., bilateral dorsal ACC and left parahippocampal gyrus, with the latter associated to cortical control of emotion and memory storage (see Bear, Connors, \& Paradiso, 2006); these activations are also likely to reflect picturing activity and the retrival of emotional memories, rather than implicit processing of the arousal level of the stimuli per se.

Lewis et al. (2007) also investigated positive and negative words separately and showed that increasing arousal for positive words enhanced activity within the ventral striatum, associated with reward and positive affect (e.g., Elliot, Friston, \& Dolan, 2000), and subgenual cingulate cortex, while increasing arousal for negative words engaged brainstem, amygdala and insula regions. Activation of ventral and dorsal striate regions in response to positive words was also reported by Hamann and Mao (2002). In addition, Straube, Sauer and Miltner (2011) showed increased vmPFC activation for positive words over negative and increased insula activation for negative words over positive ones. These results seem to support the notion that positive and negative valence are not simply ends of a continuum (Cacioppo \& Berntson, 1994; Watson et al., 1988), but rather they differ with respect to which brain regions and possibly which cognitive functions they recruit.

While these studies directly mapped the two dimensions of emotion onto patterns of brain activation, there remain some unanswered questions. First, lexical and semantic word properties of Lewis et al. (2007)'s material are unknown and might have mediated the effects found (see Larsen, Mercer, \& Balota, 2006). Second, the tasks used are not best suited to investigate implicit emotion 
processing; in fact, self-referential tasks might bias participant responses: participants more often judge positive words as referring to themselves than negative words; the task used by Posner et al., instead, involves explicit processing of the words' emotional content in addition to the retrieval of subjective, autobiographical memories.

Thus, the above reported patterns of brain activation might be driven by a wealth of factors besides valence and arousal and hence could be only partly helpful in studying the roles these variables play in emotion word processing. These aspects were considered by Kuchinke et al. (2005), who controlled their material for several lexical and semantic word properties. They reported faster lexical decision latencies and higher accuracy for positive words which, compared to neutral words, activated left orbitofrontal and superior frontal cortices, as well as middle temporal cortex bilaterally. Positive words also elicited enhanced hippocampal and anterior cingulate cortex activity over negative words. A similar advantage for positive valence was also observed during silent reading by Herbert et al. (2009), who showed enhanced engagement of the left amygdala and left extrastriate cortex in response to positive words over neutral and negative words.

The processing advantage for positive words is only partly supported by behavioural studies employing a high number of words and controlling for several lexico-semantic properties; these studies report a general advantage in lexical decision latencies for emotional words compared to neutral words (Estes \& Adelman, 2008a; Kousta, Vinson, \& Vigliocco, 2009; Larsen et al., 2006), but only a few studies report an advantage of positive words over negative ones (Estes \& Adelman, 2008a, 2008b). This partial consistency may be due to the fact that measures of brain activity might be able to pick up more subtle differences between conditions that might not arise at the behavioural level. 
The hemodynamic imaging results support the notion that positive verbal material yields a processing advantage because it is better elaborated and interconnected than negative material in the cognitive-emotional system (Ashby, Isen, \& Turken, 1999). The results are also consistent with a mood-congruent processing bias (Erickson et al., 2005). Indeed, healthy participants, not exposed to mood manipulation, are typically in a good mood and show a bias towards positive information (Fredrickson \& Branigan, 2005). This processing advantage or bias might involve implicit processes and therefore show up at the functional neural level, but not necessarily at the behavioural level.

One aim of a recent study by Citron, Gray, Critchley, Weekes and Ferstl (2011) was to independently manipulate valence and arousal dimensions using a factorial design, by carefully controlling for several lexico-semantic word properties (e.g., word frequency, imageability, age of acquisition) and by using an implicit task. Positive and negative words with low versus high arousal level were presented during a lexical decision task (LDT). Positive words showed a processing advantage, as revealed by higher accuracy and faster RTs. Interestingly, in a full-brain analysis an interaction between valence and arousal showed enhanced activation of the right anterior and posterior insular cortex in response to stimuli eliciting "conflicting" reactions when compared with emotionally congruent stimuli (cf. Robinson, 1998; Robinson, Storbeck, Meier, \& Kirkeby, 2004). Robinson et al. proposed that very intense, highly arousing stimuli elicit a withdrawal orientation or mental set, as they represent a possible threat (e.g., a very loud noise, the sudden appearance of a person while opening a door), whereas non-arousing stimuli are supposed to be safe and therefore elicit an approach orientation (e.g., encountering a colleague, receiving a newsletter). On the other hand, positive stimuli (e.g., a cake) elicit approach, whereas negative stimuli (e.g., a hole on the floor) elicit withdrawal. According to Robinson (1998), these orientations are computed at a preattentive level, independently for arousal and valence dimensions. Therefore, they need to be first integrated in order to evaluate the stimulus. Positive low-arousal (e.g., a little candy) and negative 
high-arousal stimuli (e.g., a big barking dog) will be easy to process as both their arousal and valence levels elicit congruent approach and withdrawal tendencies, respectively. Positive higharousal stimuli and negative low-arousal stimuli, instead, will elicit conflicting tendencies: for example, a rollercoaster may represent something very threatening (intense, arousing) at a first glance, but also something pleasant (positive), whereas bumping into a boring colleague at work represents a familiar and safe event (not arousing), but also something negative. Both stimuli will be more difficult to process as two opposing orientations will need to be integrated. Robinson et al. reported longer reaction times for conflicting stimuli in a series of experiments using different tasks and employing pictorial material as well as single words, but they did not investigate the neural correlates of these effects.

In Citron et al.'s (2011) study, both positive high-arousal words and negative low-arousal words elicited greater right insula activation than positive low-arousal and negative high-arousal words. The same interaction in the left insula did not reach standard significance levels. Further pair-wise comparisons showed more activation of the left parahippocampal gyrus in response to positive high-arousal words than positive low-arousal words and a trend toward a significant activation of the right posterior insula for the same contrast. No other pair-wise comparisons were significant. The insular cortex is strongly linked to viscerosensory representations of motivational states and their elaboration as emotional feelings (Craig, 1998) generated in response to both positively and negatively valenced stimuli (Jabbi, Swart, \& Keysers, 2007; Viinikainen et al., 2010). Insula activation has also been associated with empathy and with behavioural and physiological responses to risk prediction (Singer, Critchley, \& Preuschoff, 2009). Citron et al. argued that enhanced insula activation suggests integration of conflicting emotional reactions during processing of incongruent stimuli, compared to the simple coding of emotional experience required to process congruent stimuli. 
Recent evidence supporting interactive effects of valence and arousal comes from analyses of lexical decision (LD) latencies for a large word corpus (ANEW; Bradley \& Lang, 1999). Arousal was shown to modulate the speed of access to negative word representations: negative low-arousal words showed slower RTs than negative high-arousal (as well as positive) words (Larsen, Mercer, Balota, \& Strube, 2008), in line with Robinson's model.

In addition, an fMRI study comparing emotional and cognitive Stroop tasks (Compton et al., 2003), in which different arousal levels were compared within the same valence category, showed stronger attention capture by negative, highly arousing words. More specifically, the dorsolateral PFC, associated with the maintenance of the attentional focus toward target features (a word's colour), showed enhanced activation to incongruent colour words (in the classical Stroop task) as well as to negative and highly arousing words (in the emotional Stroop task). The ACC, associated with the inhibition of a salient response, was only active during the emotional Stroop task and showed enhanced activation for negative words than neutral ones and for high-arousal (positive and negative) words than low-arousal words. These results are compatible with the previous study and with Robinson et al.'s (2004) model: stimuli with negative valence or with high arousal elicit withdrawal orientations and are easier to process; therefore, their relevance and ability to quickly capture attention are higher and participants need to put more effort in order to be able to ignore the stimulus emotional content and to focus on its colour.

\subsection{What has fMRI told us about emotion word processing?}

Processing of emotionally valenced written words seems to recruit cortical and subcortical areas that typically respond to emotionally significant stimuli such as the medial PFC, ACC, insula and amygdala. Of most interest theoretically, the salience or relevance of valenced words is not uniquely determined by evaluation processes involving higher-order mental processes, as might be suggested by the activations found in ACC; rather, they also evoke automatic and less cognitively 
mediated emotional responses, as revealed by activation of the amygdala. The fMRI data support the view that emotional valence and arousal constitute distinct dimensions, as suggested by their dissociation in terms of brain activations: the former affects higher-order, more cognitivelydemanding processing levels, whereas the latter affects more perceptual, physiological and effortless levels. Nevertheless, these dimensions seem to interact in complex ways, as suggested by every study in which valence and arousal were independently manipulated (Citron et al., 2011; Compton et al., 2003; Larsen et al., 2008; Lewis et al., 2007; Posner et al., 2009). Dissociations in brain activations between positive and negative valence have also been reported, suggesting a further intrinsic differentiation of emotional valence. Furthermore, consistent evidence across fMRI studies of a processing advantage for positive words has emerged.

\section{Issues and recent progresses in understanding emotion word recognition}

\subsection{Attempts to disentangle emotional valence and arousal effects}

Most studies to date, in particular electrophysiological studies, have compared positive, negative and neutral words by matching positive and negative words for arousal and including neutral words with low arousal level. Therefore, effects of emotional valence and arousal could not be experimentally disentangled. The valence dimension is more salient because it has to do with the appraisal of an emotional situation. Arousal, instead, is associated with immediate, uncontrolled physiological and bodily reactions; this dimension is also less well-defined and is often only regarded as reflecting the intensity of a positively or negatively valenced stimulus or response. Furthermore, even though independent manipulation of valence and arousal seems the right way forward to a better understanding of emotion processing, intrinsic limitations of the linguistic material available do not make this an easy task. In fact, negative words, as well as events and concepts, tend to be naturally much more arousing than positive ones. Experimental control for this imbalance often leads to the use of mildly negative stimuli, unlike the stimuli we encounter in a natural environment. 


\subsubsection{Electrophysiological evidence for an early interaction of valence and arousal dimensions}

Attempts to rigorously manipulate emotional dimensions were pursued by Hofmann et al. (2009), Bayer, Sommer and Schacht (2010) and Citron et al. (2011). In the Hofmann et al. study, employing a LDT, negative words with high and low arousal levels were directly compared, along with comparison between positive and neutral words, both low in arousal. The arousal dimension modulated an occipito-temporal negative ERP component peaking between 80 and 120 ms, showing larger amplitude in response to negative high-arousal words and to positive words. Faster RTs for these conditions were also reported. Hofmann et al. claimed that arousal has a differential effect at early processing stages for positive and negative words; this is in line with the interactive effects of valence and arousal reported in the fMRI literature.

Through source localization, Hofmann et al. (2009) found the effect for negative higharousal words to originate in the middle-temporal and fusiform gyri, regions involved in processing of motivationally relevant material (Lang et al., 1998) and known to mediate between visual word form and higher-order, semantic stimulus processing (Martin-Loeches, Hinojosa, Gomez-Jarabo, \& Rubia, 2001). This result is in line with previous findings on the source of the RP (Hinojosa et al., 2001) and EPN (Schacht \& Sommer, 2009a) components, even though they typically appear at later latencies. Furthermore, Compton et al. (2003) reported enhanced bilateral occipito-temporal activation for negative words over neutral words and for negative high-arousal words over negative low-arousal words during an emotional Stroop task; activation of these regions was associated with processing of the distracting emotional information and therefore indexed stronger attention capture from negative, in particular high-arousal, words.

Bayer et al. (2010) presented negative high-arousal, negative low-arousal and neutral verbs embedded in sentences, during a semantic task. They reported larger LPC amplitude for negative 
high-arousal words than neutral words, but no arousal effect when valence was controlled, and claimed the relevance of this dimension for the modulation of the LPC, in line with the idea that this component reflects more elaborative processes. Nevertheless, this study could not compare arousal effects between positive and negative valence.

Citron et al. (2011) used a factorial design to orthogonally manipulate positively and negatively valenced words with high and low arousal levels during a LDT, and also included a neutral condition. The classical EPN and LPC effects were replicated, but most interestingly, a trend toward an interaction between valence and arousal was found in the EPN time-window (250$310 \mathrm{~ms}$ ), as well as in a subsequent short-lasting negativity (370-430 ms), whereby larger amplitudes were shown in response to "conflicting" positive high-arousal and negative low-arousal words than congruent positive low-arousal and negative high-arousal words (cf. Robinson et al., 2004). These results are in line with the interactive pattern of insula activation reported by the same authors (Citron et al., 2011) and complement that finding, by providing a possible time locus of this effect. The results converge on the view that the effects of emotional dimensions interact at an early stage during word processing.

\subsection{Relationships between affective, lexical and semantic word properties}

It is well-known that the sub-lexical, lexical and semantic properties of a written word have an effect on lexical decision and naming accuracy and latency (Balota, Cortese, Sergent-Marshall, Spieler, \& Yap, 2004). The investigation of emotion word processing needs to take these properties into account, otherwise effects of emotional variables might be spurious, i.e., driven by other word properties which were not controlled in the experimental paradigm (Larsen et al., 2006). Although emotion researchers have become increasingly aware of this issue - in fact, the majority of studies presented in this review control their material for several non-affective word properties - there is 
considerable scope for greater control and further analysis of the interactive effects of these variables using multi-linear methods (e.g., Yarkoni, Speer, Balota, McAvoy, \& Zacks, 2008).

\subsubsection{Word frequency and emotional valence}

To date, only a few studies have investigated the relationship between affective and non-affective word properties. This type of research can reveal a lot about which processes are involved during emotion word processing in the brain. As mentioned in Section 2.2, Scott et al. (2009) found early interactions between word frequency and emotionality (positive and negative valence), whereby high-frequency valenced words showed larger P1 and N1 amplitude than high-frequency neutral ones; this effect was reversed in the N1 for low-frequency words, showing larger amplitude in response to neutral words. The effect obtained with high-frequency words was also found in the EPN component and replicated Kissler et al.'s (2007) findings, whose words were high in frequency. A similar advantage in LDT latencies for valenced words over neutral ones was reported by Scott et al. (2009), as well as by Kuchinke et al. (2007), but only for low-frequency words; highfrequency words, instead, showed faster RTs for positive stimuli over negative and neutral ones. An interaction between valence and frequency was also reported by Kahan and Hely (2008) during an emotional Stroop task, whereby colour naming latencies to negative low-frequency words were slower than to neutral and positive words, indexing higher difficulty in ignoring the emotional connotation of negative verbal material, but only if less familiar (frequent). Finally, a very recent study by Palazova et al. (2011) also suggests an early locus of frequency by valence interactions, reporting a frequency effect only for positive words between 100-150 ms but independent main effects of frequency and emotion between 300 and $550 \mathrm{~ms}$. These results are interesting not only because they confirm that the emotional status of a word can affect very early stages of lexical access, but also because they suggest that, at least at early stages of word processing, the positiveword advantage might only occur over a certain threshold of "high frequency". This has implications for all models of word recognition and oral reading such as the Dual Route 
Computational and Parallel Distributed Models (Coltheart, Rastle, Perry, Langdon, \& Ziegler, 2001; Plaut, McClelland, Seidenberg, \& Patterson, 1996, respectively), that do not include emotional variables.

Additional support for the idea that highly frequent emotional stimuli are prioritised and therefore more easily processed comes from Nakic et al. (2006), who used a LDT. Low-frequency words elicited enhanced inferior frontal cortex activation than high-frequency ones, suggesting a role of this region in the selection of lexico-semantic representations; In addition, inferior frontal cortex activation was particularly low for highly frequent negative words, but still significant for highly frequent neutral words, suggesting facilitated processing for the former and thus no need to recruit this region. Overall, these findings suggest that very salient emotional stimuli are prioritised and more easily processed. The salience of stimuli cannot be attributed to a single variable, but to a combination of variables (high frequency, high arousal and positive valence), where affective dimensions have interactive contributions.

\subsubsection{Concreteness and emotional valence}

Another interesting study by Kanske and Kotz (2007) found an interaction between emotionality and another semantic word property called word concreteness. In a go/no-go LDT, larger amplitude on the LPC was reported in response to concrete negative words than to concrete positive and neutral words, with no differences observed for abstract words. As argued above, at this stage explicit processes related to appraisal might come into play; in fact, a more subtle discrimination between positive and negative valence has often been found in other studies (e.g., Herbert et al., 2008). However, West and Holcomb (2000) associated this component with the activation of mental imagery, reporting a larger LPC amplitude during an image generation task than either a semantic task or a shallow structural task. This result supports the dual coding model (Paivio, 1986), according to which concrete words are easier to process because they activate two 
types of mental representation: linguistic and sensory-motor. Therefore, the interaction between emotionality and concreteness reported by Kanske and Kotz (2007) might index a differential activation of mental imagery by concrete emotional and neutral words. Possibly, concrete neutral words are grounded in lexico-semantic and sensory-motor representations, whereas concrete emotional words involve lexico-semantic as well as affective representations (Kousta, Vigliocco, Vinson, Andrews, \& Del Campo, 2011).

\subsubsection{Grammatical class, lexicality and emotion}

It is well known that words belonging to different word classes are processed differently and recruit, at least in part, different brain regions: processing of nouns recruits temporal cortical regions, whereas processing of verbs recruits the prefrontal cortex (see Crepaldi, Berlingeri, Paulesu, \& Luzzatti, 2011 for an accurate and updated review). Studies on emotion word processing have used words belonging to the same class (e.g., Herbert et al., 2008; Schacht \& Sommer, 2009a) or to different classes (e.g., Scott et al., 2009) and different onsets of emotion effects have been reported depending on word class: for example, using verbs, Schacht and Sommer (2009a, 2009b) reported emotion effects on the EPN component starting approximately $150 \mathrm{~ms}$ later than the effects reported by Kissler et al. (2007) with nouns and by Herbert et al. (2008) with adjectives.

The first study that specifically addressed how word class modulates or interacts with emotional effects is Palazova et al. (2011). The authors selected nouns, adjectives and verbs and presented them during a LDT. This design was used to investigate whether the effects of emotional variables occur before or after lexical access, by comparing the onset of the lexicality and emotionality effects. They found that emotion effects (EPN) occurred approximately at the same onset as lexicality effects (negativity starting at $270 \mathrm{~ms}$ ) for nouns and adjectives, but the emotion effect followed the lexicality effect for verbs (350 versus $310 \mathrm{~ms}$, respectively), suggesting a lexical (parallel) or post-lexical locus of emotion effects. Furthermore, while the EPN in response to nouns 
showed larger amplitude for valenced words than neutral ones, the same component in response to adjectives and verbs showed an advantage for positive words only (not negative ones), compared to neutral words. Larger amplitude for positive words was also found in subsequent LPC components, along with faster RTs, for both adjectives and verbs, whereas nouns did not display any LPC or RT effect in response to the emotional content. These results replicate the bias toward positive valence within specific word classes: adjectives and verbs; their emotional content also seems to be elaborated more accurately and for a longer time, when compared to nouns. Nouns are known for being easier to process and earlier acquired (Bird, Franklin, \& Howard, 2001), in fact they also elicited faster RTs in this study than the other classes. Palazova et al. proposed that nouns might have been processed more superficially, without sustained attention toward their emotional content; alternatively, this class might be used less than others to express emotional states or events, usually expressed by adjectives and verbs, respectively.

\subsection{Different tasks used to investigate emotion word processing}

\subsubsection{Implicit and explicit emotion processing}

A cognitive task typically requires participants to process one or more characteristics of a perceptual stimulus, either by physically responding to them or by directing attention towards them. If the target characteristic corresponds to one of the experimentally manipulated variables, this variable is said to be "explicitly" processed, i.e., participants' selective attention is directed toward the variable of interest. If the target characteristic does not correspond to the experimental variable, it is assumed to be "implicitly" processed.

Tasks which require explicit processing of the emotional content of verbal stimuli consist of valence and/or arousal evaluation: participants are required either to rate emotional dimensions for each word on Likert scales or to judge them by classifying words as positive versus negative, or as emotional versus neutral. The advantage of these tasks is that they ensure emotional processing of 
the stimuli; the disadvantage is that selective attention toward the specific emotional category or rating is measured. Hence, a difference in brain activation between valenced and neutral words, for example, would be driven by both a word's affective property, the selective attention allocated to its affective connotation and processes related to explicit stimulus evaluation, which might differ from pure stimulus-driven emotion effects. Empirical evidence in this respect comes from Straube et al. (2011), who showed additional activations for emotionally valenced words compared to neutral words in the dmPFC and rostral ACC when participants were instructed to attend to the emotional meaning of the words, as opposed to when they performed an indirect task.

Tasks that require implicit emotion processing usually overcome this methodological problem. For example, the LDT, in which participants are asked to judge whether a letter string represents a real word or not, requires selective attention to the lexicality of the stimulus; Consequently, all words are explicitly processed in the same way and differences in performance between words differing in valence or arousal will be attributable to their emotional content per se, without additional influence from top-down, task-dependent processes. A behavioural study by Estes and Verges (2008) specifically investigated implicit versus explicit emotion processing and showed faster lexical decision latencies to positive words than to negative ones, but slower valence judgement latencies to positive than to negative words, suggesting the task relevance of a stimulus` emotional content can affect processing.

Another implicit task, complementary to the LDT, consists of the emotional Stroop task (a variation of the classical Stroop task; Stroop, 1935), in which participants are asked to name the colour of a word's font. Because reading is a highly automatised process, there is a conflict between the retrieval of the word's lexical representation and the colour's lexical representation, making the task effortful. Naming the colour of emotionally valenced words takes longer than neutral words, as it is more difficult to disengage attention from motivationally relevant stimuli; in this sense this task 
is complementary to the LDT, which shows facilitated and faster reactions to emotion words. The advantage of implicit tasks is that emotion processing is automatic and task-independent, but they do not necessarily ensure that participants process the emotional content of the stimuli.

Other tasks requiring implicit emotion processing have been shown to introduce some biases. A self-referential task, for example, which requires participants to judge whether or to what extent a word describes themselves, showed a bias toward positive words: people judged or rated positive words as more self-descriptive than negative or neutral words (Lewis et al., 2007). A similar effect can be seen with familiarity ratings. Familiarity represents the subjective frequency with which a person encounters a specific word. Again, participants rated positive words as more familiar (Citron et al., in press). To overcome these biases, the employment of tasks manipulating self-reference in a stimulus-driven manner might be more suitable (Herbert et al., 2011; Herbert et al., 2010). Nevertheless, the type of stimulus might also play a role; for example, Fossati et al. (2003) presented words describing positive and negative personality traits and asked participants to evaluate their self- or other-relevance. Bilateral activation of the dmPFC was reported during the self-referential task, with more robust activations for positive than negative traits.

\subsubsection{Depth of processing}

In order to ensure the affective processing of words, it is necessary to employ a task that allows access to their emotional content. Intuitively, one would think that people need to access a word's meaning in order to retrieve its emotional connotation; empirically, though, a few ERP studies have shown very early emotion effects (Hofmann et al., 2009; Scott et al., 2009) These are also seen with subliminal presentation (Bernat, Bunce, \& Shevrin, 2001; Naccache et al., 2005). Hence, a classical LDT allows the detection of processing differences between words with differing degrees of emotionality as well as a semantic task does, i.e., by asking participants to judge the congruency of the target word with a preceding "context-word" (Schacht \& Sommer, 2009a); this 
was revealed by both RT and ERP measures (i.e., EPN and LPC components). Even a more superficial structural task, consisting of judging whether a word's letters are all written in the same font, elicited differential RTs and EPN amplitudes depending on a word's emotionality; nevertheless, with this task no effects on the LPC were found (Schacht \& Sommer, 2009a). In fact, this component is task-dependent and it usually responds to differences in valence or emotionality if the task performed requires deep processing. In a variant of the LDT, consisting of the identification of meaningful words among pseudo-words, or among non-recognisable stimuli, emotional modulation of the EPN amplitude was found only in the former condition (Hinojosa et al., 2010), suggesting that a minimum degree of linguistic processing is needed to direct attention toward the affective content of words.

Silent reading of single words has also proven useful in detecting differential ERP and hemodynamic emotional responses (Herbert et al., 2009; Kissler et al., 2007). However, without collecting behavioural measures (reaction times, accuracy), it is difficult to check whether participants are actually engaged in the task. Silent reading is a viable method to avoid effects of motor responses on the ERPs; late components, as for example the LPC, occur in a time-window typically overlapping with the reaction time to a stimulus. Thus, it becomes difficult to infer whether the effects found reflect the mental processes at play or the motor-related potentials.

Another way to overcome this problem consists in the use of go/no-go tasks, whereby motor responses are only required for non-target stimuli For example, in a go/no-go LDT participants would be required to respond only to non-words. A drawback of this task is that inhibition and control processes might be used during the perception of target stimuli. This was observed by Kanske and Kotz (2007), who found a P2 effect in response to emotional words during a classical LDT, which was absent in a subsequent go/no-go task employing the same verbal material. 


\subsection{General conclusions and directions for future research}

Since the original literature review by Kissler et al. (2006), more recent electrophysiological studies, along with hemodynamic neuroimaging studies, have clearly shown that emotion variables affect written word processing at very early stages, by facilitating and enhancing processing of emotionally-relevant words and by recruiting brain areas previously associated with both more basic emotion processing (e.g., amygdala) and emotional experience (e.g., ACC, MPFC). Not only do these research findings have implications for models of written word recognition, they also show that manipulation of single words represents a suitable means to study emotion processing and that single words can elicit cortical or cerebral responses qualitatively comparable to the ones elicited by pictures and faces. Affective variables contribute to word processing beyond other lexical and semantic variables such as word frequency, age of acquisition and imageability, which are known to account for most of the variance in word recognition. More specifically, emotional valence and arousal - the two key dimensions of emotion - have been shown to directly affect different stages of word processing and to recruit brain regions associated with critical domain-general cognitive functions. Emotional valence affects later, more controlled processing stages (i.e., the LPC component), associated with evaluative processes; it also recruits brain regions activated in response to more cognitively demanding tasks, such as orbitofrontal cortex and dlPFC, suggesting that valence represents a relatively controlled "cognitive" dimension of emotion. Arousal, instead, has been shown to recruit brain regions associated with more automatic and perceptual-based processes, such as the amygdala, and arousing, emotionally valenced words produce enhanced ERP amplitudes at early processing stages (i.e., EPN); these findings suggest that arousal represents a more automatic "physiological" dimension. The research literature that has manipulated valence and arousal independently shows that these dimensions interact in complex ways, challenging the two-dimensional model. Thus, without considering the combined effects of each dimension, it will not be possible to understand emotion processing in the brain. In addition, support for a distinction 
between positive and negative valence, recruiting partially dissociable brain regions, corroborates the idea that valence does not represent a symmetrical continuum.

Studies investigating the interaction between affective and lexico-semantic variables also support the idea that valence and arousal are distinct, e.g., valence interacts with concreteness at late stages, whereas arousal affects early processing stages (e.g., EPN). On the other hand, they also show that early processing stages are modulated by interactive effects of valence, arousal and word frequency. Therefore, the prioritisation of salient, emotionally-relevant stimuli might not be entirely attributable to their emotional content per se. The present review also revealed that different types of task and their variable processing load demand can recruit very different cognitive functions. A thorough consideration of the specific task and experimental design used, depending on the research question, is therefore needed before broader theoretical claims about the effects of emotion in the brain can be made.

Future research could further investigate very early stages of emotion word processing, by carefully discerning the effects of valence, arousal and other lexical word properties. Furthermore, it is still unclear what the time locus of emotional effects is, with respect to lexical access (the retrieval of a word's lexical representation). The first study to explicitly address this issue by comparing the onsets of lexicality and emotionality effects was the one by Palazova et al. (2011), who claimed a post-lexical locus, in line with Kissler et al.'s (2007) proposal. Nevertheless, other authors consider frequency effects as an index of lexical access (Sereno et al., 1998), an effect typically occurring earlier than the lexicality effect and often interacting with emotion (e.g., Scott et al., 2009). Furthermore, lexicality indexes the success or failure of matching the word presented with an existing mental representation; this process is much faster for real words during natural reading compared with an experimental LDT in which participants have to deal with non-words as 
well. Therefore, it is not clear to what extent the time locus of the lexicality effect might be a good reference to determine whether emotion affects word processing pre- or post-lexically.

More generally, the question of how valence and arousal interact needs further investigation. Motivational relevance seems to be strongly associated with the personal relevance of the stimulus or with its "salience". In addition, individual differences in emotion word processing in healthy populations have not been addressed; gender differences seem to play a role (Bauer \& Altarriba, 2008; Sass et al., 2010; Wager et al., 2003). More importantly, emotional state and trait variables (i.e., motivation, mood and personality traits) should also to be taken into account. Furthermore, because emotional responses vary substantially depending on the circumstances (e.g., mood, environment), it would be useful to obtain ratings for the words employed in a task by each participant taking part in the study; in this way, individual variability in the perception of specific words can be controlled.

Combining different techniques to study emotion word processing has allowed complementary contributions, often helping to gain a broader picture of the topic of interest. For example, source localisation techniques have provided an estimate of the neural generator of the EPN component, supported by BOLD responses found in similar studies in the same regions. In order to better characterise which brain regions are activated at specific processing stages, the same experiment (i.e., using the same design, material and task) should be conducted with the same participants using both EEG and fMRI techniques. Another promising approach to investigate which brain areas support specific cognitive functions and at which processing stages is the study of brain-lesioned patients by means of EEG: the lesion of specific regions (e.g., the orbito-frontal cortex) might impair some ERP components but not others (see for example Paulmann, Seifert, \& Kotz, 2010). An alternative to the study of neuropsychological patients is the use of TMS (transcranial magnetic stimulation), which temporarily disrupts the functionality of specific brain 
regions, simulating a neural lesion. Finally, TMS benefits from the use of structural MRI images from each participant in order to better localise the region whose functionality will be disrupted.

The paradigms used to investigate emotion word processing by means of EEG (e.g., lexical decision, silent reading of words in isolation) typically do not allow the investigation of natural reading, whereas the use of eye-tracking techniques can shed light on how fast words are processed and how much attention they attract in a natural reading setting. Information on the time course (locus) of lexical access obtained with eye-tracking may be used as a reference to determine whether specific ERP responses index pre- or post-lexical processing stages. Recently, pupil dilation measures have proven useful in the investigation of emotion word processing (Võ et al., 2008); this method can be used during a typical word processing paradigm, as well as during natural reading, allowing direct comparisons between the two procedures. A multi-methodological approach is therefore advisable and the choice of method(s) will strongly depend on the research question.

\section{Acknowledgements}

I would like to thank Cornelia Herbert for her very helpful comments on previous versions of this manuscript and for her invaluable support. I am also grateful to Brendan Weekes for his comments and suggestions. The author is funded by an Einstein Visiting Fellowship awarded to Professor Adele Goldberg, in conjunction with the Cluster "Languages of Emotion". 


\section{References}

Abdullaev, Y. G., \& Posner, M. I. (1998). Event-related brain potential imaging of semantic encoding during processing single words. Neuroimage, 7, 1-13.

Ashby, F. G., Isen, A. M., \& Turken, U. (1999). A neuropsychological theory of positive affect and its influence on cognition. Psychological Review, 106, 529-550.

Balota, D. A., Cortese, M. J., Sergent-Marshall, S. D., Spieler, D. H., \& Yap, M. J. (2004). Visual word recognition of single-syllable words. Journal of Experimental Psychology: General, 133, 283-316.

Bauer, L. M., \& Altarriba, J. (2008). An investigation of sex differences in word ratings across concrete, abstract and emotion words. [corpus study]. The Psychological Record, 58, 465474.

Bayer, M., Sommer, W., \& Schacht, A. (2010). Reading emotional words within sentences: The impact of arousal and valence on event-related potentials. International Journal of Psychophysiology, 78, 299-307. doi: 10.1016/j.ijpsycho.2010.09.004

Bear, M. F., Connors, B. W., \& Paradiso, M. A. (2006). Neuroscience: Exploring the brain (3rd ed.). Philadelphia, PA: Lippincott Williams \& Wilkins.

Bechara, A., Damasio, H., \& Damasio, A. R. (2000). Emotion, decision making and the orbitofrontal cortex. Cerebral Cortex, 10, 295-307.

Bernat, E., Bunce, S., \& Shevrin, H. (2001). Event-related brain potentials differentiate positive and negative mood adjectives during both supraliminal and subliminal visual processing. International Journal of Psychophysiology, 42, 11-34.

Bird, H., Franklin, S., \& Howard, D. (2001). Age of acquisition and imageability ratings for a large set of words, including verbs and function words. [corpus, rating study]. Behavior Research Methods, Instruments, \& Computers, 33(1), 73-79.

Botvinick, M., Nystrom, L. E., Fissell, K., Cater, C. S., \& Cohen, J. D. (1999). Conflict monitoring versus selection-for-action in anterior cingulate cortex. Nature, 402, 179-181.

Bradley, M. M., \& Lang, P. J. (1999). Affective norms for English words (ANEW): Simuli, instruction manual and affective ratings. Gainesville, FL: The Center for Research in Psychophysiology, University of Florida.

Bush, G., Luu, P., \& Posner, M. I. (2000). Cognitive and emotional influences in anterior cingulate cortex. Trends in Cognitive Sciences, 4(6), 215-222.

Cabeza, R., \& Nyberg, L. (2000). Imaging cognition II: an empirical review of 275 PET and fMRI studies. Journal of Cognitive Neuroscience, 12(1), 1-47.

Cacioppo, J. T., \& Berntson, G. G. (1994). Relationship between attitudes and evaluative space - A critical review, with emphasis on the separability of positive and negative substrates. Psychological Bulletin, 115, 401-423. 
Carretié, L., Hinojosa, J. A., Albert, J., López-Martín, S., De La Gándara, B. S., Igoa, J. M., \& Sotillo, M. (2008). Modulation of ongoing cognitive processes by emotionally intense words. Psychophysiology, 45, 188-196. doi: 10.1111/j.1469-8986.2007.00617.x

Citron, F. M. M., Gray, M., Critchley, H. D., Weekes, B. S., \& Ferstl, E. C. (2011). Neural correlates of the interaction between emotional valence and arousal during lexical processing: Evidence for an integrated approach-withdrawal framework. Unpublished manuscript.

Citron, F. M. M., Weekes, B. S., \& Ferstl, E. C. (2011). Neural correlates of emotion word processing: The interaction between emotional valence and arousal. Psychophysiology, 48, S3-S3.

Citron, F. M. M., Weekes, B. S., \& Ferstl, E. C. (in press). How are affective word ratings related to lexico-semantic properties? Evidence from the Sussex Affective Word List (SAWL). Applied Psycholinguistics.

Colibazzi, T., Posner, J., Wang, Z., Gorman, D., Gerber, A., Yu, S., . . Russell, J. A. (2010). Neural systems subserving valence and arousal during the experience of induced emotion. Emotion, 10, 377-389. doi: 10.1037/a0018484

Coltheart, M., Rastle, K., Perry, C., Langdon, R., \& Ziegler, J. C. (2001). DRC: A dual route cascaded model of visual word recognition and reading aloud. Psychological Review, 108, 204-256.

Compton, R. J., Banich, M. T., Mohanty, A., Milham, M. P., Herrington, J., Miller, G. A., . . . Heller, W. (2003). Paying attention to emotion: An fMRI investigation of cognitive and emotional Stroop tasks. Cognitive, Affective \& Behavioural Neuroscience, 3, 81-96. doi: 10.3758/CABN.3.2.81

Craig, A. D. B. (1998). A new version of the thalamic dishinibition hypothesis of central pain. Pain forum, 7, 1-14.

Crepaldi, D., Berlingeri, M., Paulesu, E., \& Luzzatti, C. (2011). A place for nouns and a place for verbs? A critical review of neurocognitive data on grammatical-class effects. Brain and Language, 116, 33-49. doi: 10.1016/j.bandl.2010.09.005

Elliot, R., Friston, K. J., \& Dolan, R. J. (2000). Dissociable neural responses in human reward systems. The Journal of Neuroscience, 20, 6159-6165.

Erickson, K., Drevets, W. C., Clark, L., Cannon, D. M., Bain, E. E., Zarate, C. A., . . Sahakian, B. J. (2005). Mood-congruent bias in affective go/no-go performance of unmedicated patients with major depressive disorder. American Journal of Psychiatry, 162, 2171-2173.

Estes, Z., \& Adelman, J. S. (2008a). Automatic vigilance for negative words in lexical decision and naming: Comment of Larsen, Mercer, and Balota (2006). Emotion, 8, 441-444. doi: DOI: $10.1037 / 1528-3542.8 .4 .441$

Estes, Z., \& Adelman, J. S. (2008b). Automatic vigilance for negative words is categorical and general. Comment reply. Emotion, 8, 453-457. doi: DOI: 10.1037/a0012887

Estes, Z., \& Verges, M. (2008). Freeze or flee? Negative stimuli elicit selective responding. Cognition, 108, 557-565. doi: 10.1016/j.cognition.2008.03.003 
Feldman Barrett, L., \& Russell, J. A. (1998). Independence and bipolarity in the structure of current affect. Journal of Personality and Social Psychology, 74, 967-984.

Fischler, I., \& Bradley, M. M. (2006). Event-related potential studies of language and emotion: Words, phrases and task effects. Progress in Brain Research, 156, 185-203.

Fossati, P., Hevenor, S. J., Graham, S. J., Grady, C., Keightley, M. L., Craik, F., \& Mayberg, H. (2003). In search of the emotional self: an fMRI study using positive and negative emotional words. American Jouornal of Psychiatry, 160, 1938-1945.

Franken, I. H. A., Gootjes, L., \& van Strien, J. W. (2009). Automatic processing of emotional words during an emotional Stroop task. NeuroReport, 20, 776-781. doi: 10.1097/WNR.0b013e32832b02fe

Fredrickson, B. L., \& Branigan, C. (2005). Positive emotions broaden the scope of attention and thought-action repertoires. Cognition and Emotion, 19, 313-332. doi: $10.1080 / 02699930441000238$

Garavan, H., Pendergrass, J. C., Ross, T. J., Stein, E. A., \& Risinger, R. C. (2001). Amygdala response to both positively and negatively valenced stimuli. NeuroReport, 12, 2779-2783.

Gootjes, L., Coppens, L. C., Zwaan, R. A., Franken, I. H. A., \& van Strien, J. W. (2011). Effects of recent word exposure on emotion-word Stroop interference: An ERP study. International Journal of Psychophysiology, 79, 356-363. doi: 10.1016/j.ijpsycho.2010.12.003

Hamalainen, M. S., \& Ilmoniemi, R. J. (1994). Interpreting magnetic fields of the brain: Minimum norm estimates. Medical and Biological Engineering and Computing, 32, 35-42.

Hamann, S., \& Mao, H. (2002). Positive and negative emotional verbal stimuli elicit activity in the left amygdala. NeuroReport, 13, 15-19.

Herbert, C., Ethofer, T., Anders, S., Junghofer, M., Wildgruber, D., Grodd, W., \& Kissler, J. (2009). Amygdala activation during reading of emotional adjectives - an advantage for pleasant content. Social Cognitive and Affective Neuroscience, 4, 35-49. doi: $10.1093 / \mathrm{scan} / \mathrm{nsn} 027$

Herbert, C., Herbert, B. M., Ethofer, T., \& Pauli, P. (2011). His or mine? The time course of selfother discrimination in emotion processing. Social Neuroscience, 6, 277-288. doi: $10.1080 / 17470919.2010 .523543$

Herbert, C., Junghofer, M., \& Kissler, J. (2008). Event related potentials to emotional adjectives during reading. Psychophysiology, 45, 487-498. doi: 10.1111/j.1469-8986.2007.00638.x

Herbert, C., Kissler, J., Junghöfer, M., Peyk, P., \& Rockstroh, B. (2006). Processing of emotional adjectives: Evidence from startle EMG and ERPs. Psychophysiology, 43, 197-206. doi: $10.1111 / \mathrm{j} .1469-8986.2006 .00385 . \mathrm{x}$

Herbert, C., Pauli, P., \& Herbert, B. M. (2010). Self-reference modulates the processing of emotional stimuli in the absence of explicit self-referential appraisal instructions. Social Cognitive and Affective Neuroscience, 2, 303-312. doi: 10.1093/scan/nsq082

Hinojosa, J. A., Carretié, L., Valcarcel, M. A., Méndez-Bértolo, C., \& Pozo, M. A. (2009). Electrophysiological differences in the processing of affective information in words and 
pictures. Cognitive, Affective \& Behavioural Neuroscience, 9, 173-189. doi: 10.3758/CABN.9.2.173

Hinojosa, J. A., Martin-Loeches, M., \& Rubia, F. J. (2001). Event-related potentials and semantics: an overview and an integrative proposal. Brain and Language, 78, 128-139. doi: 10.1006/brln.2001.2455

Hinojosa, J. A., Méndez-Bértolo, C., \& Pozo, M. A. (2010). Looking at emotional words is not the same as reading emotional words: Behavioural and neural correlates. Psychophysiology, 47, 748-757. doi: 10.1111/j.1469-8986.2010.00982.x

Hofmann, M. J., Kuchinke, L., Tamm, S., Võ, M. L.-H., \& Jacobs, A. M. (2009). Affective processing within 1/10th of a second: High arousal is necessary for early facilitative processing of negative but not positive words. Cognitive, Affective \& Behavioural Neuroscience, 9, 389-397. doi: 10.3758/9.4.389

Isenberg, N., Silbersweig, D., Engelien, A., Emmerich, S., Malavade, K., Beattie, B., . . Stern, E. (1999). Linguistic threat activates the human amygdala. Proceedings of the National Academy of Sciences of the USA, 96, 10456-10459.

Ito, T. A., Cacioppo, J. T., \& Lang, P. J. (1998). Eliciting affect using the international affective picture system: Trajectories through evaluative space. Personality and Social Psychology Bulletin, 24, 855-879.

Jabbi, M., Swart, M., \& Keysers, C. (2007). Empathy for positive and negative emotions in the gustatory cortex. NeuroImage, 34, 1744-1753. doi: 10.1016/j.neuroimage.2006.10.032

Jones, C. L., Ward, J., \& Critchley, H. D. (2010). The neuropsychological impact of insular cortex lesions. Journal of Neurology, Neurosurgery \& Psychiatry, 81, 611-618. doi: 10.1136/jnnp.2009.193672

Junghöfer, M., Bradley, M. M., Elbert, T. R., \& Lang, P. J. (2001). Fleeting images: A new look at early emotion discrimination. Psychophysiology, 38, 175-178. doi: $10.1017 / \mathrm{S} 0048577201000762$

Junghöfer, M., Sabatinelli, D., Bradley, M. M., Schupp, H. T., Elbert, T. R., \& Lang, P. J. (2001). Fleeting images: rapid affect discrimination in the visual cortex. NeuroReport, 17, 225-229. doi: 10.1097/01.wnr.0000198437.59883.bb

Kahan, T. A., \& Hely, C. D. (2008). The role of valence and frequency in the emotional Stroop task. Psychonomic Bulletin \& Review, 15, 956-960. doi: 10.3758/PBR.15.5.956

Kanske, P., \& Kotz, S. A. (2007). Concreteness in emotional words: ERP evidence from a hemifield study. Brain Research, 1148, 138-148. doi: 10.1016/j.brainres.2007.02.044

Kanske, P., \& Kotz, S. A. (2011). Emotion triggers executive attention: Anterior cingulate cortex and amygdala responses to emotional words in a conflict task. Human Brain Mapping, 32, 198-208. doi: 10.1002/hbm.21012

Kensinger, E. A., \& Schacter, D. L. (2006). Processing emotional pictures and words: effects of valence and arousal. Cognitive, Affective \& Behavioural Neuroscience, 6, 110-126. 
Kissler, J., Assadollahi, R., \& Herbert, C. (2006). Emotional and semantic networks in visual word processing: insights from ERP studies. Progress in Brain Research, 156, 147-183. doi: 10.1016/S0079-6123(06)56008-X

Kissler, J., Herbert, C., Peyk, P., \& Junghofer, M. (2007). Buzzwords. Early cortical responses to emotional words during reading. Psychological Science, 18, 475-480.

Kissler, J., Herbert, C., Winkler, I., \& Junghofer, M. (2009). Emotion and attention in visual word processing - An ERP study. Biological Psychology, 80, 75-83. doi: 10.1016/j.biopsycho.2008.03.004

Kotz, S. A., \& Paulmann, S. (2011). Emotion, language, and the brain. Language and Linguistics Compass, 5, 108-125. doi: 10.1111/j.1749-818x.2010.00267.x

Kousta, S.-T., Vigliocco, G., Vinson, D. P., Andrews, M., \& Del Campo, E. (2011). The representation of abstract words: Why emotion matters. Journal of Experimental Psychology: General, 1, 14-34. doi: 10.1037/a0021446

Kousta, S.-T., Vinson, D. P., \& Vigliocco, G. (2009). Emotion words, regardless of polarity, have a processing advantage over neutral words. Cognition, 112, 473-481. doi: 10.1016/j.cognition.2009.06.007

Kringelbach, M. L. (2005). The human orbitofrontal cortex: Linking reward to hedonic experience. Nature Reviews Neuroscience, 6, 691-702.

Kuchinke, L., Jacobs, A. M., Gubrich, C., Võ, M. L.-H., Conrad, M., \& Herrmann, M. (2005). Incidental effects of emotional valence in single word processing: An fMRI study. NeuroImage, 28, 1022-1032. doi: 10.1016/j.neuroimage.2005.06.050

Kuchinke, L., Schlochtermeier, L., \& Jacobs, A. M. (2011). Differences in the neural processing of emotional pictures and words are modulated by stimulus complexity. Psychophysiology, 48, S3-S3.

Kuchinke, L., Võ, M. L.-H., Hofmann, M., \& Jacobs, A. M. (2007). Pupillary responses during lexical decisions vary with word frequency but not emotional valence. International Journal of Psychophysiology, 65, 132-140. doi: 10.1016/j.ijpsycho.2007.04.004

Kutas, M., \& Federmeier, K. D. (2000). Electrophysiology reveals semantic memory use in language comprehension. Trends in Cognitive Neuroscience, 4, 463-470.

Lang, P. J., Bradley, M. M., \& Cuthbert, B. N. (1997). Motivated attention: Affect, activation, and action. In P. J. Lang, R. F. Simons \& M. T. Balaban (Eds.), Attention and orienting: Sensory and motivational processes (pp. 97-135). Hillsdale, NJ: Erlbaum.

Lang, P. J., Bradley, M. M., \& Cuthbert, B. N. (1999). International Affective Picture System (IAPS): instruction manual and affective ratings. Gainsville, FL: The Center for Research in Psychophysiology, University of Florida.

Lang, P. J., Bradley, M. M., Fitzsimmons, J. R., Cuthbert, B. N., Scott, J. D., Moulder, B., \& Nangia, V. (1998). Emotional arousal and activation of the visual cortex: an fMRI analysis. [fMRI]. Psychophysiology, 35, 199-210. 
Larsen, R. J., Mercer, K. A., \& Balota, D. A. (2006). Lexical characteristics of words used in emotional Stroop experiments. Emotion, 6, 62-72. doi: 10.1037/1528-3542.6.1.62

Larsen, R. J., Mercer, K. A., Balota, D. A., \& Strube, M. J. (2008). Not all negative words slow down lexical decision and naming speed: Importance of word arousal. Emotion, 8, 445-452. doi: 10.1037/1528-3542.8.4.445

Lau, E. F., Phillips, C., \& Poeppel, D. (2008). A cortical network for semantics: (de)constructing the N400. Nature Reviews Neuroscience, 9, 920-933.

Levenson, R. W. (2011). Basic emotion questions. Emotion Review, 3, 1-8.

Levy, R., \& Goldman-Rakic, P. S. (2000). Segregation of working memory functions within the dorsolateral prefrontal cortex. Experimental Brain Research, 133, 23-32.

Lewis, P. A., Critchley, H. D., Rotshtein, P., \& Dolan, R. J. (2007). Neural correlates of processing valence and arousal in affective words. Cerebral Cortex, 17, 742-748. doi: 10.1093/cercor/bhk024

MacDonald, A. W. (2000). Dissociating the role of the dorsolateral prefrontal and anterior cingulate cortex in cognitive control. Science, 288, 1835-1838.

Marslen-Wilson, W., \& Tyler, L. K. (1980). The temporal structure of spoken language understanding. Cognition, 8, 1-71.

Martin-Loeches, M. (2007). The gate for reading: Reflections on the recognition potential. Brain Research Reviews, 53, 89-97. doi: 10.1016/j.brainresrev.2006.07.001

Martin-Loeches, M., Hinojosa, J. A., Gomez-Jarabo, G., \& Rubia, F. J. (2001). An early electrophysiological sign of semantic processing in basal extrastriate areas. Psychophysiology, 38, 114-124. doi: 10.1111/1469-8986.3810114

Mishkin, M., Ungerleider, L. G., \& Macko, K. A. (1983). Object vision and spatial vision - 2 cortical pathways. Trends in Neurosciences, 6, 414-417. doi: 10.1016/0166-2236(83)90190$\mathrm{X}$

Naccache, L., Gaillard, R., Adam, C., Hasboun, D., Clémenceau, S., Baulac, M., . . Cohen, L. (2005). A direct intracranial record of emotions evoked by subliminal words. Proceedings of the National Academy of Sciences of the USA, 102, 7713-7717. doi: 10.1073 pnas.0500542102

Nakic, M., Smith, B. W., Busis, S., Vythilingam, M., \& Blair, J. R. (2006). The impact of affect and frequency on lexical decision: The role of amygdala and inferior frontal cortex. NeuroImage, 31, 1752-1751. doi: 10.1016/j.neuroimage.2006.02.022

Newman, J. D. (1978). Perception of sounds used in species-specific communication: the auditory cortex and beyond. Journal of Medical Primatology, 7, 98-105.

Osgood, C. E., Suci, G. J., \& Tannenbaum, P. H. (1957). The measurement of meaning. Urbana, Chicago, and London: University of Illinois Press.

Paivio, A. (1986). Mental representations: A dual coding approach. Oxford: Oxford University Press. 
Palazova, M., Mantwill, K., Sommer, W., \& Schacht, A. (2011). Are effects of emotion in single words non-lexical? Evidence from event-related brain potentials. Neuropsychologia, 49, 2766-2775. doi: 10.1016/j.neuropsychologia.2011.06.005

Paulmann, S., Seifert, S., \& Kotz, S. A. (2010). Orbito-frontal lesions cause impairment in late but not early emotional prosodic processing stages. Social Neuroscience, 5, 59-75.

Pell, M. D., Jaywant, A., Monetta, L., \& Kotz, S. A. (2011). Emotional speech processing: Disentangling the effects of prosody and semantic cues. Cognition and Emotion, 25, 834853. doi: dx.doi.org/10.1080/02699931.2010.516915

Phan, K. L., Wager, T., Taylor, S. F., \& Liberzon, I. (2002). Functional neuroanatomy of emotion: a meta-analysis of emotion activation studies in PET and fMRI. NeuroImage, 16, 331-348.

Plaut, D. C., McClelland, J. L., Seidenberg, M. S., \& Patterson, K. (1996). Understanding normal and impaired word reading: Computational principles in quasi-regular domains. Psychological Review, 103, 56-115.

Polich, J. (2007). Updating P300: An integrative theory of P3a and P3b. Clinical Neurophysiology, 118, 2128-2148. doi: 10.1016/j.clinph.2007.04.019

Polli, F. E., Barton, J. J. S., Cain, M. S., Thakkar, K. N., Rauch, S. L., \& Manoach, S. (2005). Rostral and dorsal anterior cingulate cortex make dissociable contributions during antisaccade error commission. Proceedings of the National Academy of Sciences of the USA, 102, 15700-15705. doi: 10.1073 pnas.0503657102

Posner, J., Russell, J. A., Gerber, A., Gorman, D., Colibazzi, T., Yu, S., . . Peterson, B. S. (2009). The neurophysiological bases of emotion: an fMRI study of the affective circumplex using emotion-denoting words. Human Brain Mapping, 30, 883-895. doi: 10.1002/hbm.20553

Potter, M. C. (1975). Meaning in visual search. Science, 187, 965-966.

Reisenzein, R. (1994). Pleasure-arousal theory and the intensity of emotions. [Theoretical]. Journal of Personality and Social Psychology, 67(3), 525-539.

Robinson, M. D. (1998). Running from William James' bear: A review of preattentive mechanisms and their contributions to emotional experience. Cognition and Emotion, 12(5), 667-696.

Robinson, M. D., Storbeck, J., Meier, B. P., \& Kirkeby, B. S. (2004). Watch out! That could be dangerous: Valence-arousal interactions in evaluative processing. Personality and Social Psychology Bulletin, 30, 1472-1484. doi: 10.1177/0146167204266647

Russell, J. A. (1980). A circumplex model of affect. Journal of Personality and Social Psychology, 39, 1161-1178.

Russell, J. A. (1991). Culture and the categorization of emotions. Psychological Bulletin, 110, 426450.

Russell, J. A. (2003). Core affect and the psychological construction of emotion. [Theoretical]. Psychological Review, 110(1), 145-172. 
Sabatinelli, D., Bradley, M. M., Fitzsimmons, J. R., \& Lang, P. J. (2005). Parallel amygdala and inferotemporal activation reflect emotional intensity and fear relevance. NeuroImage, 24, 1265-1270. doi: 10.1016/j.neuroimage.2004.12.015

Sass, S. M., Heller, W., Stewart, J. L., Silton, R. L., Edgar, C., Fisher, J. E., \& Miller, G. A. (2010). Time course of attentional bias to threat in anxiety: Emotion and gender specificity. Psychophysiology, 47, 247-259. doi: 10.1111/j.1469-8986.2009.00926.x

Schacht, A., \& Sommer, W. (2009a). Time course and task dependence of emotion effects in word processing. Cognitive, Affective \& Behavioural Neuroscience, 9, 28-43. doi: 10.3758/CABN.9.1.28

Schacht, A., \& Sommer, W. (2009b). Emotions in word and face processing: Early and late cortical responses. Brain and Cognition, 69, 538-550. doi: 10.1016/j.bandc.2008.11.005

Scherg, M., \& Berg, P. (2000). BESA (Version 5.0.4). Munich, Germany: Megis.

Schupp, H. T., Junghöfer, M., Weike, A. I., \& Hamm, A. O. (2004). The selective processing of briefly presented affective pictures: An ERP analysis. Psychophysiology, 41, 441-449. doi: 10.1111/j.1469-8986.2004.00174.x

Schupp, H. T., Stockburger, J., Codispoti, M., Junghöfer, M., Weike, A. I., \& Hamm, A. O. (2006). Stimulus novelty and emotion perception: the near absence of habituation in the visual cortex. Neuroreport, 17, 365-369. doi: 10.1097/01.wnr.0000203355.88061.c6

Scott, G. G., O'Donnell, P. J., Leuthold, H., \& Sereno, S. C. (2009). Early emotion word processing: Evidence from event-related potentials. Biological Psychology, 80, 95-104. doi: 10.1016/j.biopsycho.2008.03.010

Sereno, S. C., \& Rayner, K. (2003). Measuring word recognition in reading: eye movements and event-related potentials. Trends in Cognitive Sciences, 7, 489-493. doi: 10.1016/j.tics.2003.09.010

Sereno, S. C., Rayner, K., \& Posner, M. I. (1998). Establishing a time-line of word recognition: evidence from eye movements and event-related potentials. NeuroReport, 9, 2195-2200.

Singer, T., Critchley, H. D., \& Preuschoff, K. (2009). A common role of insula in feelings, empathy and uncertainty. Trends in Cognitive Sciences, 13, 334-340. doi: 10.1016/j.tics.2009.05.001

Small, D. M., Gregory, M. D., Mak, Y. E., Gitelman, D., Mesulam, M. M., \& Parrish, T. (2003). Dissociation of neural representation of intensity and affective valuation in human gustation. Neuron, 39, 701-711.

Straube, T., Sauer, A., \& Miltner, W. H. R. (2011). Brain activation during direct and indirect processing of positive and negative words. Behavioural Brain Research, 222, 66-72. doi: 10.1016/j.bbr.2011.03.037

Stroop, J. R. (1935). Studies of interference in serial-verbal reactions. Journal of Experimental Psychology, 18, 643-662.

Viinikainen, M., Jääskeläinen, I. P., Alexandrov, Y., Balk, M. H., Autti, T., \& Sams, M. (2010). Nonlinear relationship between emotional valence and brain activity: evidence of separate 
negative and positive valence dimensions. Human Brain Mapping, 31, 1030-1040. doi: $10.1002 / \mathrm{hbm} .20915$

Võ, M. L.-H., Jacobs, A. M., Kuchinke, L., Hofmann, M. J., Conrad, M., Schacht, A., \& Hutzler, F. (2008). The coupling of emotion and cognition in the eye: Introducing the pupil old/new effect. Psychophysiology, 45, 130-140. doi: 10.1111/j.1469-8986.2007.00606.x

Wager, T. D., Phan, K. L., Liberzon, I., \& Taylor, S. F. (2003). Valence, gender, and lateralization of functional brain anatomy in emotion: a meta-analysis of findings from neuroimaging. NeuroImage, 19, 513-531.

Watson, D., Clark, L. A., \& Tellegen, A. (1988). Development and validation of brief measures of positive and negative affect - The PANAS scales. Journal of Personality and Social Psychology, 54(6), 1063-1070.

West, W. C., \& Holcomb, P. J. (2000). Imaginal, semantic, and surface-level processing of concrete and abstract words: An electrophysiological investigation. Journal of Cognitive Neuroscience, 12, 1024-1037.

Wierzbicka, A. (1999). Emotions across languages and cultures: diversity and universals. Cambridge, UK: Cambridge University Press.

Winston, J. S., Gottfried, J. A., Kilner, J. M., \& Dolan, R. J. (2005). Integrated neural representations of odor intensity and affective valence in human amygdala. Journal of Neuroscience, 25, 8903-8907. doi: 10.1523/jneurosci.1569-05.2005

Winston, J. S., O'Doherty, J., \& Dolan, R. J. (2003). Common and distinct neural responses during direct and incidental processing of multiple facial emotions. Neuroimage, 20, 84-97. doi: $10.1016 / \mathrm{s} 1053-8119(03) 00303-3$

Yarkoni, T., Speer, N. K., Balota, D. A., McAvoy, M. P., \& Zacks, J. M. (2008). Pictures of a thousand words: Investigating the neural mechanisms of reading with extremely rapid eventrelated fMRI. NeuroImage, 42, 973-987. doi: 10.1016/j.neuroimage.2008.04.258 


\section{Table and Figure Caption}

Table 1. Schematic summary of all ERP studies reviewed in the article, with details regarding the task, material and design used. Behavioural results are reported, along with the ERP components found to be modulated by emotional variables.

Figure 1. Early Posterior Negativity (EPN), from Herbert, Junghöfer and Kissler (2008). This component usually peaks between 200 and $300 \mathrm{~ms}$, has negative polarity and occipito-temporal scalp distribution. Its amplitude is typically larger for emotionally valenced stimuli (positive and negative) than neutral stimuli.

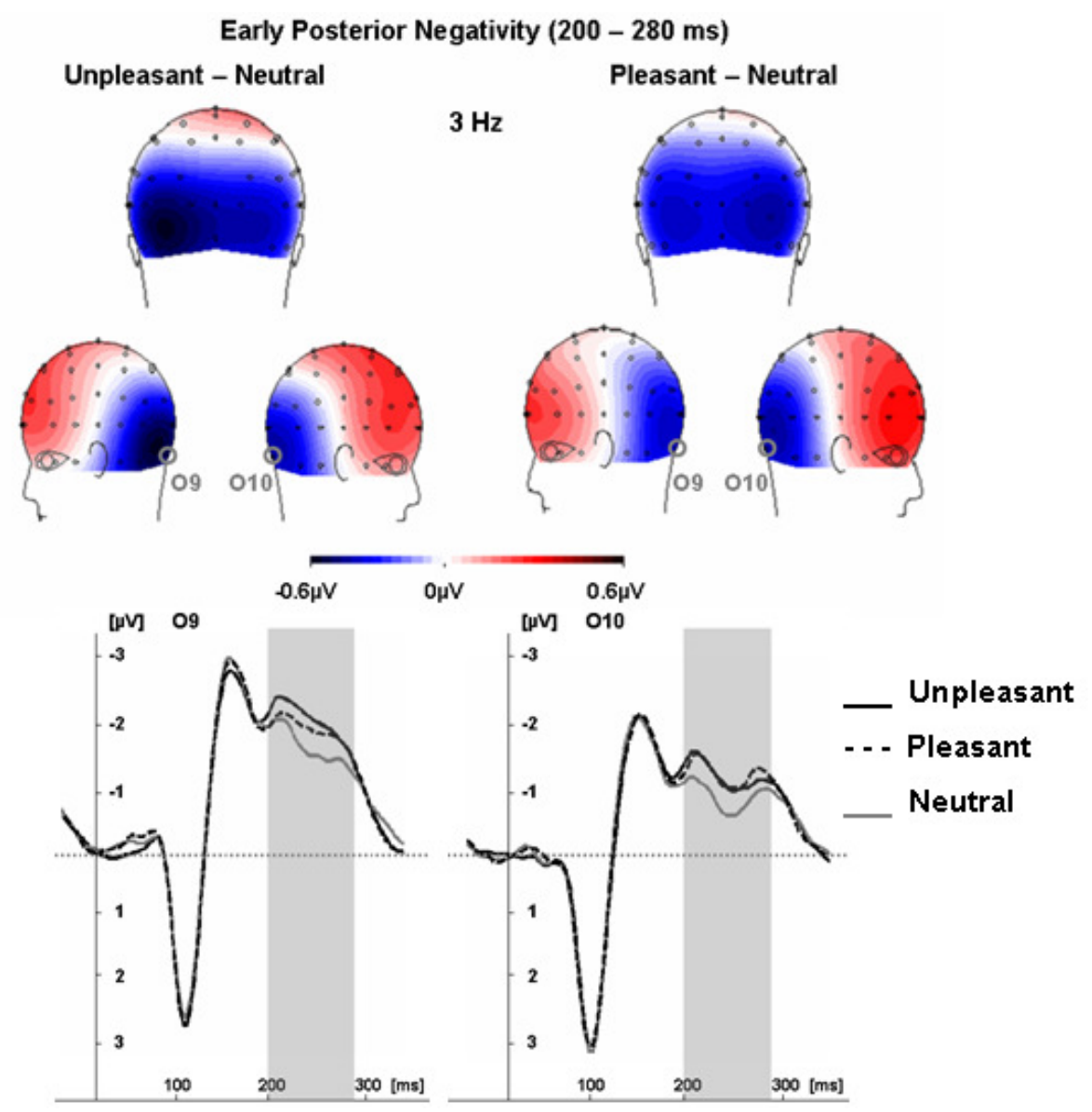


Figure 2. Late positive complex (LPC), also called late posterior positivity (LPP), from Herbert, Junghöfer and Kissler (2008). This component usually peaks between 500 and $800 \mathrm{~ms}$, has positive polarity and centro-parietal scalp distribution. Its amplitude has been shown do respond to the valence dimension; in this case, positive words elicit larger amplitude than neutral and negative words.

\section{LPP $(470-600 \mathrm{~ms})$}

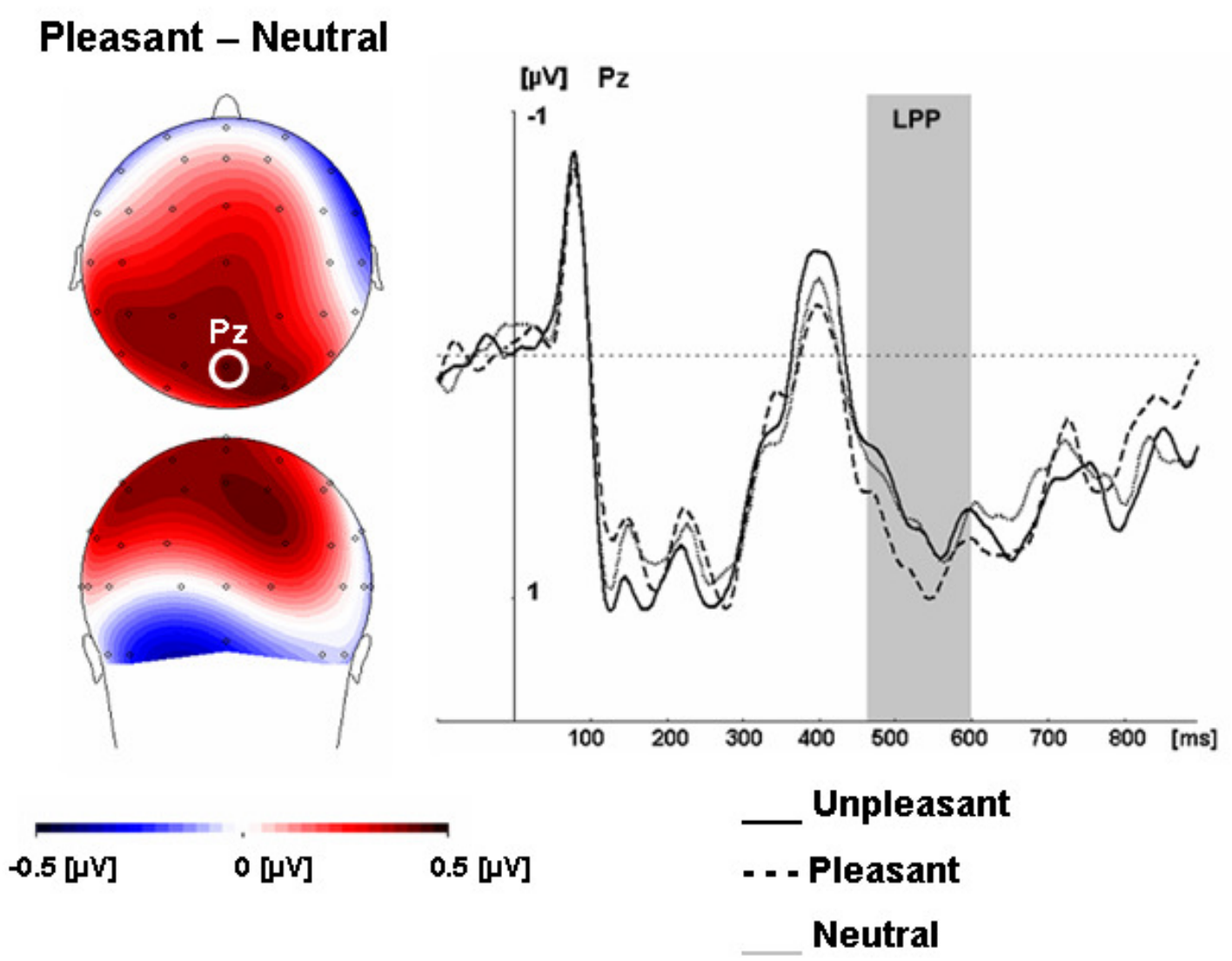


Table 1.

\begin{tabular}{|c|c|c|c|c|c|c|c|}
\hline study & Task & $\begin{array}{l}\text { Number and type of stimuli } \\
\text { (pres. duration per stimulus) }\end{array}$ & Other variables controlled & Stimuli source & Non-ERP measures, effects found & $\begin{array}{l}\text { Analysed ERP components } \\
\text { (time window), electrodes }\end{array}$ & ERP effects found and direction \\
\hline $\begin{array}{l}\text { Herbert, Kissler, } \\
\text { Junghoffer, Peyk \& } \\
\text { Rockstroh (2006) }\end{array}$ & $\begin{array}{l}\text { Covert emotional } \\
\text { evaluation (pleasant, } \\
\text { unpleasant, neutral) } \\
\text { and memorisation }\end{array}$ & $\begin{array}{l}60 \text { pleasant, } 60 \text { unpleasant and } 60 \\
\text { neutral adjectives ( } 5000 \mathrm{~ms}) ; 20 \text { trials } \\
\text { each accompanied by startle probes } \\
\text { (2500-4000 ms after word onset) }\end{array}$ & $\begin{array}{l}\text { Word length, frequency, arousal } \\
\text { within valenced words }\end{array}$ & $\begin{array}{l}\text { Norms for valence and arousal: } \\
500 \text { adjectives rated by } 45 \\
\text { students }\end{array}$ & $\begin{array}{l}\text { Startle eyeblink: blink facilitation } \\
\text { for pleasant words }\end{array}$ & $\begin{array}{l}\text { N1 (50-180 ms), parieto-occipital; P2 (180-250 } \\
\text { ms), P3 (250-400 ms), LPC ( } 600-750 \mathrm{~ms}) \text {, centro- } \\
\text { parietal. }\end{array}$ & $\begin{array}{l}\text { N1: n.e., P2, P3: pleasent+unpleasant > neutral; LPC: } \\
\text { - pleasant > negative+neutral }\end{array}$ \\
\hline $\begin{array}{l}\text { Kissler, Herbert, } \\
\text { Pevk \& Junghöfer } \\
\text { (2007) }\end{array}$ & $\begin{array}{l}\text { Silent reading; surprise } \\
\text { free-recall task }\end{array}$ & $\begin{array}{l}60 \text { pleasant, } 60 \text { unpleasant and } 60 \\
\text { neutral nouns presented } 10 \text { times in } 10 \\
\text { randomised rapid serial visual } \\
\text { presentation (RSVP) sequences, } 5 \text { tast } \\
(333 \mathrm{~ms} \text { per word), } 5 \text { slow (1000 ms) }\end{array}$ & $\begin{array}{l}\text { Word length, trequency, } \\
\text { concreteness, arousal within } \\
\text { valenced words }\end{array}$ & $\begin{array}{l}\text { Norms tor valence and arousal: } \\
300 \text { nouns rated by } 45 \text { students }\end{array}$ & $\begin{array}{l}\text { No. ot words recalled: } \\
\text { pleasant+unpleasant > neutral }\end{array}$ & EPN (200-300 ms), occipito-temporal & $\begin{array}{l}\text { EPN: pleasent+unpleasant > neutral with lett hemisphere } \\
\text { advantage across repetitions and sequence rates, more } \\
\text { pronounced for fast sequence rate; SOURCE: left extra-striate } \\
\text { cortex }\end{array}$ \\
\hline \multirow[t]{2}{*}{$\begin{array}{l}\text { Kanske \& Kotz } \\
(2007)\end{array}$} & $\begin{array}{l}\text { Exp. 1: lexical decision } \\
\text { task (LDT) }\end{array}$ & $\begin{array}{l}60 \text { positive, } 60 \text { negative and } 120 \text { neutral } \\
\text { nouns (200 ms), right and left visual } \\
\text { field (R/LVF), half words high and half } \\
\text { low in concreteness, length 4-8 letters; } \\
240 \text { pronounceable non-words }\end{array}$ & $\begin{array}{l}\text { Noun gender, word length, } \\
\text { frequency }\end{array}$ & $\begin{array}{l}\text { Norms for valence and } \\
\text { concreteness: } 720 \text { nouns rated } \\
\text { by } 40 \text { students }\end{array}$ & $\begin{array}{l}\text { Reaction times (RTS): concrete < } \\
\text { abstract; RVF < LVF; } \\
\text { positive+negative < neutral: } \\
\text { positive < negative, only for } \\
\text { concrete words }\end{array}$ & $\begin{array}{l}\text { P2 (210-300 ms), N400 (390-590 ms), LPC (590- } \\
\text { 750 ms), whole scala, } 4 \text { regions of interest } \\
\text { (ROIs): anterior right hemisphere (RH), anterior } \\
\text { left hemisphere (LH), posterior RH, posterior } \\
\text { G2LH }\end{array}$ & $\begin{array}{l}\text { P2: positive > neutral, RVF }>\text { LVF; N400: concrete > abstract, } \\
\text { neutral > positive+negative, both stronger in anteriorily, the } \\
\text { latter stronger in LH, RVF }>\text { LVF; LPC: abstract }>\text { concrete, } \\
\text { stronger anteriorily, positive+negative }>\text { neutral, LVF }>\text { RVF }\end{array}$ \\
\hline & Exp. 2: go/no-go LDT & Same material & $\begin{array}{l}\text { In addition: arousal within valenced } \\
\text { words }\end{array}$ & $\begin{array}{l}\text { Additional norms for arousal: } \\
720 \text { nouns rated by } 30 \text { students }\end{array}$ & No RTs collected & Same parameters & $\begin{array}{l}\text { P2: absent; N400: main effects replicated, no interactions; } \\
\text { LPC: main effects replicated, emotion effect only for concrete } \\
\text { words, negative > positive+neutral }\end{array}$ \\
\hline $\begin{array}{l}\text { Herbert, Junghöfer } \\
\text { \& Kisster (2008) }\end{array}$ & $\begin{array}{l}\text { Silent reading; surprise } \\
\text { free-recall task }\end{array}$ & $\begin{array}{l}60 \text { pleasant, } 60 \text { unpleasant and } 60 \\
\text { reutral adjectives presented } 10 \text { times ir } \\
10 \text { randomised RSVP sequences, } 5 \text { fast } \\
(333 \text { ms per word), } 5 \text { slow (1000 ms) }\end{array}$ & $\begin{array}{l}\text { Word length, frequency, } \\
\text { nighbuurtuoud density, bigrarn } \\
\text { frequency, arousal within valenced } \\
\text { words }\end{array}$ & $\begin{array}{l}\text { Herbert et al. (2006). Additional } \\
\text { norms for concreteness: } 500 \\
\text { adjectives rated by } 31 \text { students }\end{array}$ & Recall accuracy: pleasant> neutral & $\begin{array}{l}\text { P1 (80-130 ms), parieto-occipital; N1 (130-190), } \\
\text { EPN (200-280 ms), pusterior; N400 (360-470 } \\
\text { ms), medial, medio-lateral, centro-parietal }\end{array}$ & 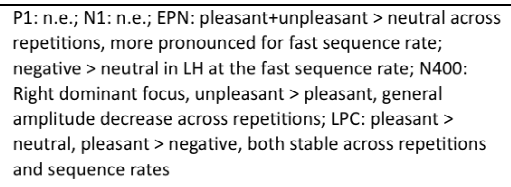 \\
\hline $\begin{array}{l}\text { Carretié et al. } \\
\text { (2008) }\end{array}$ & LDT & $\begin{array}{l}10 \text { insults, } 10 \text { compliments, } 10 \text { neutral } \\
\text { adjectives, } 30 \text { legible non-words } \times 3 \\
\text { repetitions }(650 \mathrm{~ms})\end{array}$ & $\begin{array}{l}\text { Number of syllables, arousal within } \\
\text { valenced words }\end{array}$ & $\begin{array}{l}\text { Norms for valence and arousal: } \\
50 \text { insults, } 50 \text { compliments, } 50 \\
\text { neutral adjectives rated by } 2 \\
\text { indipendent samples of } 37 \text { and } \\
50 \text { women }\end{array}$ & $\begin{array}{l}\text { RTs: compliments < } \\
\text { insults+neutral; Accuracy: } \\
\text { complimentstneutral > insults }\end{array}$ & $\begin{array}{l}\text { Latency and amplitude analyses: } P 2 \text { ( (235-275 } \\
\mathrm{ms} \text { ), LPC ( } 520-800 \mathrm{~ms}), 4 \text { regions (horisontal } \\
\text { stripes): prefrontal, frontal, central, posterior }\end{array}$ & $\begin{array}{l}\text { P2: n.e.; LPC Latency: insults > compliments+neutral in } \\
\text { frontal, central and posterior regions; Amplitude: } \\
\text { compliments > neutral in central and posterior regions, } \\
\text { insults > neutral in the central region }\end{array}$ \\
\hline $\begin{array}{l}\text { Scott, O'Donnell, } \\
\text { Leuthold \& Sereno } \\
\text { (2009) }\end{array}$ & LDT & $\begin{array}{l}80 \text { positive, } 80 \text { negative, } 80 \text { neutral, half } \\
\text { high and half low in word frequency } \\
\text { (HF, LF), } 240 \text { pronounceble non-words, } \\
\text { presentation until response (up to } 2000 \\
\text { mis) }\end{array}$ & $\begin{array}{l}\text { Word length, frequency accoss } \\
\text { positive, negative and neutral } \\
\text { conditions, arousal within valenced } \\
\text { words }\end{array}$ & ANEW (Bradley \& Lang, 2009) & $\begin{array}{l}\text { RTS: positive+negative < neutral; } \\
\mathrm{HF}<\mathrm{LF} \text { i interaction with LF: } \\
\text { positive+negative }<\text { neutral, } H F ; \\
\text { positive }<\text { negative+neutral }\end{array}$ & $\begin{array}{l}\text { P1 (80-120 ms), N1 (135-180 ms), EPN (200-300 } \\
\text { ms), posterior electrodes, RH and LH; P3 (300- } \\
\text { 450), parietal midline }\end{array}$ & 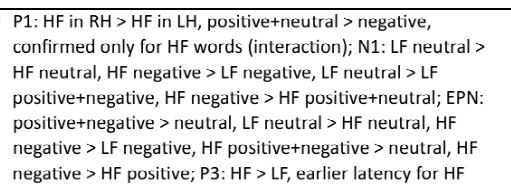 \\
\hline \multirow[t]{2}{*}{$\begin{array}{l}\text { Kissler, Herbert, } \\
\text { Winkler \& } \\
\text { Junghöfer (2009) }\end{array}$} & $\begin{array}{l}\text { Silent reading; surprise } \\
\text { free-recall task }\end{array}$ & $\begin{array}{l}99 \text { adjectives, } 99 \text { nouns, within each } \\
\text { class: } 33 \text { positive, } 33 \text { negative, } 33 \\
\text { neutral ( } 680 \mathrm{~ms} \text {, no ISI) }\end{array}$ & $\begin{array}{l}\text { Word length, frequency, } \\
\text { nighbourhood density (N-density), } \\
\text { bigram frequency, arousal within } \\
\text { valenced words }\end{array}$ & $\begin{array}{l}\text { Herbert et al. (2006); Herbert et } \\
\text { al. (2008) }\end{array}$ & $\begin{array}{l}\text { Recall accuracy: pleasant > } \\
\text { negative+neutral }\end{array}$ & $\begin{array}{l}\text { EPN (240-300 ms), LPC (470-570 ms), occipito- } \\
\text { parietal }\end{array}$ & $\begin{array}{l}\text { EPN: positive > neutral, negative > neutral; LPC: positive > } \\
\text { negative }\end{array}$ \\
\hline & $\begin{array}{l}\text { Counting adjectives; } \\
\text { counting nouns }\end{array}$ & Same material & Same variables & Same source & & $\begin{array}{l}\text { Same parameterss; in addition frontal LPC (450-- } \\
650 \mathrm{~ms} \text { ), fronto-central (task effects more } \\
\text { centrally distributed) }\end{array}$ & $\begin{array}{l}\text { EPN: pasitive > neutral, negative }>\text { neutral, target adjjectives } \\
>\text { non-target adjectives; : LPC: positive }>\text { nutral, nouns }> \\
\text { adjectives disappearing upon repetitions; frontal LPC: target } \\
\text { words }>\text { non-target words }\end{array}$ \\
\hline
\end{tabular}


Neural correlates of emotion word processing

240 verbs: positive, negative, neutral in Word frequency, orthographic $\mathrm{N}$ - Own unpublished norms equal proportions, 240 pronounceable size, length in letters and syllables, (valence)

non-words, prese
(up to $2700 \mathrm{~ms}$ )

valenced words

RTs: positive neegative < neutral
Accuracy: positive > neutral

Negativity (368-488 ms), parieto-occipital

Negativity: positive+negative $>$ neutral

Exp. 2. Structural task 3 sets of 120 word pairs: a noun (500 Target verbs: word frequency, first OWn unoublished norms for $\quad$ RTs: positive +negative $<$ neutral, Parieto-occipital negativity and frontal positivity $180-292 \mathrm{~ms}$ : positive thegative $>$ neutral, SOURCE: fusiform -

semantic task verb in infinite form (presentation until

Pairs: imageanhility word length. target verbs (valence) and wity

airs: imageability, arousal within pairs (arousal, imageas

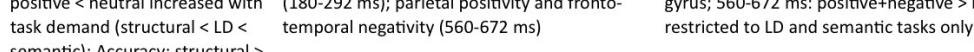

(congruency with

response up to $1500 \mathrm{~ms})$; 3 sets of 120 valenced words; positive pairs
distractor word pairs

higher association stre
negative and neutral. semantic); ; Accuracy: structu

neutral+negative,

\begin{tabular}{|c|c|c|c|c|c|c|c|}
\hline $\begin{array}{l}\text { Schact \& Sommer } \\
\text { (2009b) }\end{array}$ & LDT & $\begin{array}{l}40 \text { positive, } 40 \text { negative, } 40 \text { neutral } \\
\text { verbs, } 120 \text { pronounceable non-words, } \\
\text { presentation until response (up to } 2700 \\
\text { ms) }\end{array}$ & Schacht \& Sommer (2009a) & Schacht \& Sommer (2009a) & $\begin{array}{l}\text { RTs: positive+negative < neutral; } \\
\text { Accuracy: n.e. }\end{array}$ & $\begin{array}{l}\text { Parieto-occipital negativity and frontal positivity } \\
\text { (388-438, } 438-488 \mathrm{~ms}) \text {; parietal positivity and } \\
\text { fronto-temporal negativity }(538-638 \mathrm{~ms})\end{array}$ & $\begin{array}{l}\text { 388-438, } 438-488 \text { ms: positive > neutral; } 538-638 \text { ms: } \\
\text { negative >neutral }\end{array}$ \\
\hline $\begin{array}{l}\text { Hofmann, } \\
\text { Kuchinke, Tamm, } \\
\text { Vō \& Jacobs (2009) }\end{array}$ & LDT & $\begin{array}{l}200 \text { nouns, } 4-8 \text { letters long }(1000 \mathrm{~ms}): \\
50 \text { negative high in arousal (NH), } 50 \\
\text { negative low in arousal ( }(\mathrm{LL}), 50 \text { positive } \\
\text { low (PL), and } 50 \text { neutral; } 200 \\
\text { pronounceable non-words, }\end{array}$ & $\begin{array}{l}\text { Arousal matched among NL, PL, } \\
\text { neutral words, valence matched } \\
\text { btw. NH, NL words. Control for: } \\
\text { word length, frequency, N-size, } \\
\text { imagaeability, mean letter and } \\
\text { bigram frequencies }\end{array}$ & BAWL-R (Võ et al., 2009) & $\begin{array}{l}\text { RTs: } \mathrm{PL}<\text { neutral, } \mathrm{NH}< \\
\mathrm{NL}+\mathrm{Neutral} \text {, neutral }<\mathrm{NL} ; \\
\text { Accuracy: } \mathrm{PL}>\text { neutral, } \mathrm{NH}>\mathrm{NL}\end{array}$ & $\begin{array}{l}\text { 80-120 ms, 140-190 ms, EPN (200-250 ms), LPC } \\
\text { (-50-750 ms), } 4 \text { ROIs: anterior RH, anterior LH, } \\
\text { posterior RH, posterior LH. 80-120 ms } \\
\text { submitted to sLORETA }\end{array}$ & 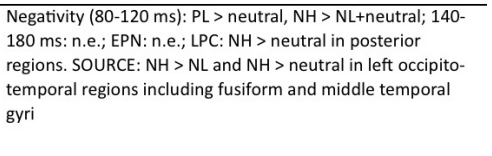 \\
\hline $\begin{array}{l}\text { Hinojosa, Carretié, } \\
\text { Valcárel, Méndez- } \\
\text { Bétrolo \& Pozo } \\
\text { (2009) }\end{array}$ & $\begin{array}{l}\text { word identification } \\
\text { among nonsense stimuli } \\
\text { (letter fragments spread } \\
\text { on the screen) }\end{array}$ & $\begin{array}{l}80 \text { nouns ( } 20 \text { positive, } 20 \text { negative, } 20 \\
\text { relaxing, } 20 \text { neutral), } 80 \text { background } \\
\text { stimuli, rapid stream stimulation } \\
\text { procedure ( } 250 \mathrm{~mm} \text { stimulus onset } \\
\text { asynchrony, Hinojosa et al., 2001) }\end{array}$ & $\begin{array}{l}\text { Word length, frequency, } \\
\text { concreteness, arousal within } \\
\text { valenced words, valence between } \\
\text { positive and relaxing words }\end{array}$ & $\begin{array}{l}\text { Norms for valence, arousal } \\
\text { concreteness: } 720 \text { nouns rated } \\
\text { by } 45 \text { participants }\end{array}$ & RTs: n.e. & $\begin{array}{l}\text { EPN (225-275), parieto-occipital, with frontal } \\
\text { positive counterpart; positivity (350-425), } \\
\text { parietal, with frontal negative counterpart }\end{array}$ & EPN: n.e.; positivity: neutral > positive+relaxing+neutral \\
\hline \multirow[t]{2}{*}{$\begin{array}{l}\text { Hinojosa, Méndez- } \\
\text { Bértolo \& Pozo } \\
\text { (2010) }\end{array}$} & $\begin{array}{l}\text { Exp 1: word } \\
\text { identification among } \\
\text { non-recognisable } \\
\text { stimuli }\end{array}$ & $\begin{array}{l}240 \text { nouns ( } 80 \text { positive, } 80 \text { negative, } 80 \\
\text { neutral), } 80 \text { non-recognisable stimuli } \\
\text { (RSVP) }\end{array}$ & $\begin{array}{l}\text { Word length, frequency, } \\
\text { concreteness, arousal within } \\
\text { valenced words }\end{array}$ & $\begin{array}{l}\text { Norms for valence, arousal } \\
\text { concreteness: } 720 \text { nouns rated } \\
\text { by } 45 \text { participants }\end{array}$ & RTs: n.e. Omissions: n.e. & $\begin{array}{l}\text { EPN (225-300 ms), posterior, with frontal } \\
\text { positive counterpart; LPC (550-650 ms), central }\end{array}$ & EPN: n.e.; LPC: n.e. \\
\hline & $\begin{array}{l}\text { Exp. 2: word } \\
\text { identification among } \\
\text { pseudo words }\end{array}$ & $\begin{array}{l}240 \text { nouns ( } 80 \text { positive, } 80 \text { negative, } 80 \\
\text { neutral), } 80 \text { non-words (RSVP) }\end{array}$ & Same variables & Same source & $\begin{array}{l}\text { RTS: positive }<\text { negative+neutral; } \\
\text { Omissions: positive } \\
\text { negative+neutral }\end{array}$ & Same parameters & $\begin{array}{l}\text { EPN: positive > negative+neutral; LPC: positive+negative > } \\
\text { neutral }\end{array}$ \\
\hline $\begin{array}{l}\text { Bayer, Sommer \& } \\
\text { Schacht (2010) }\end{array}$ & Semantic decision task & $\begin{array}{l}262 \text { correct German verb-final } \\
\text { sentences in future tense. } 2 \text { subsets } \\
\text { analysed: } 100 \text { sentencees, } 50 \text { negative } \\
\text { high-arousal, } 50 \text { neutral low-arousal; } 48 \\
\text { sentence pairs, equal valence, different } \\
\text { arousal levels. } 262 \text { sentences with } \\
\text { semantically inappropriate final verbs. } \\
\text { Durations: sentence } 1000 \mathrm{~ms} \text {, interval } \\
500 \mathrm{~ms} \text {, target verb until reponse (max } \\
2000 \mathrm{~ms} \text { ) }\end{array}$ & $\begin{array}{l}\text { Word length, frequency and } \\
\text { expectedness fo the final verb }\end{array}$ & $\begin{array}{l}\text { Own norms and material from } \\
\text { previous experiments (Schacht \& } \\
\text { Sommer 2009a; 2009b) }\end{array}$ & $\begin{array}{l}\text { Expectancy ratings: appropriate > } \\
\text { inappropriate sentences; neutral } \\
\text { low-arousal > negative high- } \\
\text { arousal sentencecs. RTs: } \\
\text { appropriate }<\text { inapropriate } \\
\text { sentences }\end{array}$ & $\begin{array}{l}\text { Positivity (LPC) at parietal electrodes (326-426 } \\
\text { ms); negativity at central electrodes (326-426 } \\
\text { ms;) Iong-lasting negativity at centro-parietal } \\
\text { electrodes (from 276 }\end{array}$ & $\begin{array}{l}\text { positivity (LPC): negative high-arousal > neutral l low-arousal } \\
\text { verbs; negativity: high-arousal ss. low-arousal verb; long- } \\
\text { lasting negativity inappropriate > appropriate verbs }\end{array}$ \\
\hline Sass et al. (2010) & $\begin{array}{l}\text { Emotional Stroop task. } \\
\text { Anxious vs. healthy and } \\
\text { female vis. male } \\
\text { participants (only data } \\
\text { from healthy } \\
\text { participants are } \\
\text { reported here) }\end{array}$ & $\begin{array}{l}256 \text { trials in } 16 \text { blocks ( } 4 \text { pleasant, } 8 \\
\text { neutral, } 4 \text { threat): } 64 \text { pleasant, } 64 \\
\text { threat (both high in arousal) and } 128 \\
\text { neutral words, 3-to-8 } 8 \text { letters long (1500 } \\
\text { ms) }\end{array}$ & Length in letters, frequency & ANEW (Bradley \& Lang, 2009) & RTs: $m e n<$ women & $\begin{array}{l}\text { P1 at parieto-occipital electrodes }(88-128 \mathrm{~ms}), \\
\text { N2 at parieto-occipital electrodes }(160-240 \mathrm{~ms}), \\
\text { P3 at centro-parietal electrodes }(448-580 \mathrm{~ms}) \text {, i } \\
\text { N400 at fronto-central electrodes }(448-580 \mathrm{~ms})\end{array}$ & $\begin{array}{l}\text { P1: women > men; RH > LH; threat > pleasant words in } \\
\text { males; N2: arousing > neutral words; pleasant }>\text { treat words } \\
\text { in males; P3 } \mathrm{Pl} \text { (latency): threat > pleasant tords for females; } \\
\text { N400: neutral > arousing words; } \mathrm{LH}>\mathrm{RH}\end{array}$ \\
\hline $\begin{array}{l}\text { Palazova, } \\
\text { Mantwill, Sommer } \\
\text { \& Schacht (2011) }\end{array}$ & LDT & $\begin{array}{l}180 \text { words: } 60 \text { adjective, } 60 \text { nouns, } 60 \\
\text { verbs, half high and half low in } \\
\text { frequency (HF, LF), } 1 / 3 \text { neutral, } 1 / 3 \\
\text { positive and } 1 / 3 \text { negative in valence; } \\
180 \text { pseudo words. Word presented } \\
\text { until reponse (max } 1500 \mathrm{~ms} \text { ) }\end{array}$ & Word length, imageability & $\begin{array}{l}\text { Own norms and BAWL (Vō et al. } \\
\text { 2006) }\end{array}$ & 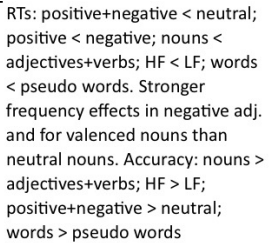 & 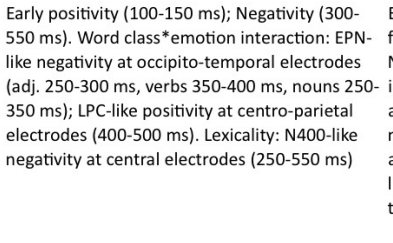 & 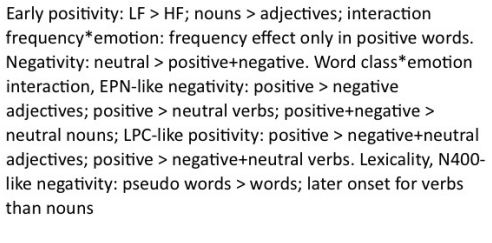 \\
\hline
\end{tabular}

